NBER WORKING PAPER SERIES

\title{
WEALTHIER, HAPPIER AND MORE SELF-SUFFICIENT: WHEN ANTI-POVERTY PROGRAMS IMPROVE ECONOMIC AND SUBJECTIVE WELLBEING AT A REDUCED COST TO TAXPAYERS
}

\author{
Titus J. Galama \\ Robson Morgan \\ Juan E. Saavedra \\ Working Paper 24090 \\ http://www.nber.org/papers/w24090 \\ NATIONAL BUREAU OF ECONOMIC RESEARCH \\ 1050 Massachusetts Avenue \\ Cambridge, MA 02138 \\ November 2017
}

Research reported in this publication was supported by the National Institute on Aging of the National Institutes of Health under Award Numbers P01AG022481, K02AG042452 and R01AG037398. The content is solely the responsibility of the authors and does not necessarily represent the official views of the National Institutes of Health. Titus Galama is grateful to the School of Economics of Erasmus University Rotterdam for a Visiting Professorship in the Economics of Human Capital. The views expressed herein are those of the authors and do not necessarily reflect the views of the National Bureau of Economic Research.

NBER working papers are circulated for discussion and comment purposes. They have not been peer-reviewed or been subject to the review by the NBER Board of Directors that accompanies official NBER publications.

(C) 2017 by Titus J. Galama, Robson Morgan, and Juan E. Saavedra. All rights reserved. Short sections of text, not to exceed two paragraphs, may be quoted without explicit permission provided that full credit, including $\odot$ notice, is given to the source. 
Wealthier, Happier and More Self-Sufficient: When Anti-Poverty Programs Improve Economic and Subjective Wellbeing at a Reduced Cost to Taxpayers

Titus J. Galama, Robson Morgan, and Juan E. Saavedra

NBER Working Paper No. 24090

November 2017

JEL No. H53,I30,I32,I38,O38,O54

\begin{abstract}
We document how an anti-poverty program improves economic and subjective wellbeing, and self-sufficiency. Familias en Accion Urbano, a conditional cash transfer program implemented at scale in the country of Colombia, uses a means-test cutoff score selection rule that provides exogenous variation in program participation. We reproduce the score assignment rule in a nationally representative living standards household survey that measures multiple dimensions of economic and evaluative wellbeing. Three years into the program, beneficiary households at the margin report greater income, consumption and formal employment participation for both the household head and partner. Household income increased by ten times the amount of the government transfer, likely because of gains in formal employment. Beneficiary households at the margin also report greater overall satisfaction with life, greater happiness and greater satisfaction with food. These results support the hypothesis that among households with basic unmet needs, policies that have a permanent impact on income and consumption may also have a lasting impact on subjective wellbeing and self-sufficiency. Moreover, relatively small subsidies, further offset by additional government tax receipt, may generate substantial benefits to poor families at a reduced cost to taxpayers.
\end{abstract}

Titus J. Galama

Dornsife Center for Economic and Social Research University of Southern California

635 Downey Way

Los Angeles, CA 90089

galama@usc.edu

Robson Morgan

Dornsife Center for Economic and Social Research University of Southern California

635 Downey Way

Los Angeles, CA 90089

rhmorgan@usc.edu
Juan E. Saavedra

Dornsife Center for Economic and Social Research University of Southern California

635 Downey Way

Los Angeles, CA 90089

and NBER

juansaav@usc.edu 


\section{Introduction}

It is unclear whether anti-poverty programs can have lasting impacts on economic wellbeing, subjective wellbeing and self-sufficiency, while mitigating the costs to taxpayers. Critics argue, for example, that anti-poverty programs are costly redistribution programs that promote government dependency through reduced work incentives (e.g., Murray 1984). Alternatively, these programs may expand participants' choice sets (e.g., through improved nutrition) enabling them to take advantage of labor-market opportunities, and by increasing selfsufficiency, reduce the burden on taxpayers.

In this paper we empirically address this question in the context of Familias en Accion Urbano (FAU), a conditional cash transfer program implemented at scale in the country of Colombia. FAU targets socioeconomically disadvantaged households in Colombia's fourteen largest cities, which concentrate over 80 percent of the country's population. At full scale, Familias en Accion (rural plus urban expansion) benefits over two million households nationwide. For eligible households, FAU provides cash transfers to families with children under the age of 18 conditional on medical visits for younger children and school enrollment and continued attendance for secondary school students. ${ }^{1}$

We take advantage of the fact that a means-test score determines FAU eligibility. As we demonstrate with the aid of administrative baseline data, the means-test score provides exogenous variation in program participation near the program eligibility cutoff. We then reproduce the means-test score assignment rule in a nationally representative Colombian living standards household survey collected three years into the program. The survey measures multiple dimensions of evaluative wellbeing as well as more objective measures that include income, consumption, health and education, and that lacks the incentives for strategic reporting because it was not designed to explicitly target program beneficiaries or track program-related outcomes (e.g., Camacho and Conover 2011).

Three years, in particular, is a relatively long time frame to study whether or not impacts are permanent. For instance, Di Tella et al. (2007) find that, among German households, life satisfaction fully adapts to changes in income within four years.

\footnotetext{
${ }^{1}$ FAU does not provide cash subsidies for primary-school children, since primary school enrollment in Colombia's major cities is nearly universal.
} 
Three years into the program, beneficiary households at the margin of eligibility report greater income, consumption and formal employment participation for both household head and partner. Impacts on household income at the margin are a factor of ten times greater than would be expected solely on the basis of the cash transfers, likely because of gains in formal employment. This finding casts doubt on the notion that anti-poverty programs always generate work disincentives and is consistent with recent evidence from other cash transfer programs (Banerjee et al. 2016).

Increases in consumption that result from program participation map almost one to one to increases in income, and there is a substantial increase on food expenditures among beneficiary households at the margin, which may have influenced the quantity and quality of nutritional intakes. ${ }^{2}$ Through enhanced choice sets, anti-poverty programs like Colombia's conditional cash transfer program may open new avenues for increased market opportunities among beneficiary households.

The fact that reported household income at the margin is ten times average transfer size, and is likely due to greater formal employment participation of household head and partner, suggests that a portion of the subsidy is offset by additional government tax receipt. A simple back-of envelope calculation suggests that-for marginal applicants-the actual cost to taxpayers is about 40 percent of actual program costs, and may even be zero or negative if the calculation is based on alternative regression specifications.

Participating households at the margin report, three years into the program, greater overall satisfaction with life and greater happiness. These households also report greater satisfaction with food. While we cannot conclude from these results that increasing income increases subjective wellbeing, the results suggest that anti-poverty programs simultaneously enhance economic wellbeing, subjective wellbeing and self-sufficiency. These results are consistent with the hypothesis that greater income-presumably through consumption-can improve happiness for households with unmet basic needs (Veenhoven 1991).

Despite large increases in income, consumption, formal employment and overall satisfaction with life and happiness, participant households on the margin of eligibility do not report greater satisfaction with income or work. This is consistent with the hypothesis that the

\footnotetext{
2 These results are consistent with earlier evidence on the impacts of CCT programs on household consumption (Filmer and Schady 2009).
} 
evaluative assessment of one's income is based on a reference point, such as the income of others (e.g., Kahneman et al. 2005). In the case of the FAU, the lack of improved satisfaction with income or work could be due to the head and partner of participant households being significantly more likely to hold a formal sector job and therefore interacting with more affluent peers (e.g., Luttmer 2005).

The paper contributes to a longstanding debate, although few studies establish causally the effects of social assistance and social insurance programs on economic and subjective wellbeing. Finkelstein et al. (2012) show that random access to health insurance (uninsured lowincome adults in Oregon were selected by lottery to be given the chance to apply for Medicaid) increased health-service utilization and improved subjective wellbeing of low-income adults. Boyd-Swan et al. (2016) use the 1990 federal earned income tax credit (EITC) expansion, and Kuhn et al. (2011) and Gardner and Oswald (2007) use lottery winnings to explore the effect of income on subjective wellbeing. These studies suggest that large monetary gains (relative to income) causally improve subjective wellbeing, but small ones do not.

In the developing world, existing studies typically provide information on the short-term impacts (at most one year) of small-scale, or pilot, anti-poverty programs on subjective wellbeing. It is, therefore, unclear whether improvements in wellbeing that result from these interventions are permanent or transitory and how they would fare implemented at large scale. Baird, De Hoop, and Özler (2013) use a randomized cash-transfer experiment in Malawi to estimate psychological effects of unconditional and conditional cash transfers. Compared to the control group, unconditional and conditional cash transfers diminished psychological stress a few months after the two-year intervention ended. Relative to the unconditional cash-transfer group, however, the conditional cash-transfer group maintained a higher level of stress, presumably due to the constraint provided by the transfer conditions.

Haushofer and Shapiro (2016) also used a randomized controlled trial in which poor rural households in Kenya were randomly assigned to receive large unconditional cash transfers (at least two months of average household consumption). The transfers significantly improved consumption and subjective wellbeing four months (on average) after the end of the program. Devoto et al. (2012) find positive effects on life satisfaction five to six months after implementation of a pilot social program in Morocco providing interest-free loans to households to cover the cost of connecting the household directly to piped water. Cattaneo et al. (2009) find 
that a large-scale program in Mexico to replace dirt floors with cement floors improved the health of young children and adult welfare in terms of reductions in depression, perceived stress, and increased satisfaction with floor quality, house quality and quality of life.

To summarize, our main contribution to this nascent literature is threefold. We document how a conditional cash transfer anti-poverty program can simultaneously improve material and subjective conditions for participants, and increase their self-sufficiency. By simultaneously measuring objective and subjective measures of wellbeing our results may shed light on potential pathways by which anti-poverty programs can improve wellbeing among households with unmet needs. Second, our findings suggest that achieving those goals can sometimes be achieved at a reduced cost to taxpayers, to the extent that anti-poverty programs help enhance participants' market opportunities. Third, we introduce a potentially new research methodology in which we reproduce complex program assignment rules in public-use household survey data, enabling researchers to simultaneously observe multiple measures of economic and subjective wellbeing at a low cost (data are public use), without attrition (households do not differentially leave the sample as a result of the program as the survey is not directly tied to the program), and without the incentives for strategic reporting that pervade many program evaluation surveys (since, again, the survey is not tied to the program).

The remainder of the paper proceeds as follows. Section 2 presents an overview of the FAU program. Section 3 describes the data. Section 4 describes the methods employed and the research design. Section 5 presents results, and section 6 concludes.

\section{The Familias en Accion Conditional Cash Transfer Program}

In 2001, Colombia introduced Familias en Accion, a conditional cash-transfer program modeled after Mexico's PROGRESA. ${ }^{3}$ Familias en Accion targets low-income households with children in rural areas and cities with less than 100,000 inhabitants. It provides cash transfers to the target population, conditional on young children attending regular medical checkups and school-age children enrolling and continually attending school.

In 2007, the Colombian government introduced Familias en Accion Urbano (FAU), an extension of Familias en Accion to include low-income households with children in Colombia's fourteen largest cities: Barranquilla, Bogota, Bucaramanga, Cali, Ibague, Medellin, Monteria,

\footnotetext{
${ }^{3}$ Programa de Educación, Salud, y Alimenación (program for education, health and nutrition).
} 
Neiva, Pasto, Pereira, Santamarta, Sincelejo, Villavicencio and Yopal. The FAU program is the focus of this study.

The Colombian government uses the SISBEN score as the means-test score that determines eligibility for all social programs in the country, including FAU, subsidized healthcare, job training and child support. Each program has a different cutoff point. SISBEN scores range from 0 to 100 and can take any value in between, including non-integer values. To participate in FAU, households need to document that, at the time of program launch, they have a SISBEN $^{4}$ score below the 11-point eligibility cutoff and have children under the age of 18 residing in the household.

To determine eligibility for FAU in 2007, the government used the means-test score from the SISBEN 2005 census of the poor. To create SISBEN scores, the government uses an (undisclosed) weighting scheme that takes into account households socio-economic characteristics, including the material living standard of the dwelling (type of floor and roof materials, number of rooms, type of stove, access to piped water, sewage, electricity and trash collection), strata (a proxy measure of socio-economic status based on neighborhood of residence), household size, education of the household head and his/her partner and formal employment of the head and his/her partner (couples include those married or cohabitating). Since the SISBEN census of the poor is at the household level, all individuals residing within a household have the same SISBEN score.

In addition to being a resident of a program city, having a SISBEN score of 11 points or lower and having children under the age of 18, participation in FAU requires households to meet certain program conditions. For households with children under the age of one, these children must see a doctor for checkups every two months. Children between one and two years of age must see a doctor for checkups three times a year, and children between two and seven years of age must see a doctor for checkup twice a year. FAU imposes no medical visit conditions on children 11 years of age and older. ${ }^{5}$ Instead, these children must be enrolled in school and must have at least an 80 percent school attendance rate, which is verified every two months.

\footnotetext{
${ }^{4}$ Sistema de Potenciales Beneficiarios para Programas Sociales (system of potential beneficiaries for social programs).

${ }^{5}$ Primary school enrollment is not subsidized and there are no FAU medical visit conditions for ages 8 to 11.
} 
Participation in FAU entitles households to two types of subsidies: nutritional and educational. Throughout, nominal Colombian pesos (COP) subsidy amounts at the start of FAU are translated into 2010 USD (see Appendix A for detail).

Nutritional Subsidy: Households with any number of children between zero and six years of age and households with any number of children in both the zero to six and the seven to eleven years of age groups that meet the above eligibility conditions receive a nutritional subsidy of \$31/month. Households with any number of children between seven and eleven years of age that meet eligibility conditions receive a nutritional subsidy of $\$ 12 /$ month. Households with children ages 12 and above do not receive a nutritional subsidy.

Educational Subsidy: The FAU educational subsidy amount is contingent on school grade, not age. Households with children attending elementary school receive no subsidy. ${ }^{6}$ For households with children attending secondary school and meeting eligibility criteria, the subsidy amount increases with school grade and depends on the program modality adopted in the city of residence.

There are three FAU modalities: savings, incremental and Medellin (Inter-American Development Bank and World Bank 2006). ${ }^{7}$

Savings modality: The cities of Bogota, Barranquilla, Bucaramanga, Monteria, Pasto, Pereira, Villavicencio and Yopal adopted an FAU program modality with a savings modality, modeled after a pilot project in Bogota (Barrera-Osorio et al., 2011). In the savings modality, eligible households with students in grades 6 through 8 receive a subsidy of $\$ 16 /$ month, eligible households with students in grades 9 and 10 receive a subsidy of $\$ 22 /$ month, and eligible households with students in grade 11 receive a subsidy of $\$ 25 /$ month. Eligible household also receive a one-time (savings) subsidy of $\$ 81$ when a child passes grade 9 and enrolls in grade 10, and a one-time subsidy of $\$ 187$ when a child successfully graduates from secondary school (i.e. passes grade 11).

Incremental modality: The cities of Ibague, Neiva, Santa Marta and Sincelejo adopted the incremental modality. In the incremental modality, eligible households with students in grades 6 through 8 receive a subsidy of $\$ 19 /$ month, eligible households with students in grades 9 and 10

\footnotetext{
${ }^{6}$ Primary school enrollment at baseline in FAU program cities was close to universal, which is presumably why the government subsidizes secondary, but not primary, school enrollment and attendance. Medellin and Cali, however, operate the rural modality, which also includes an elementary school subsidy.

7 The rural version of Famillias en Accion constitutes a fourth modality, but is not studied in this paper.
} 
receive a subsidy of $\$ 28 /$ month, and eligible households with students in grade 11 receive a subsidy of $\$ 37 /$ month. $^{8}$ In the incremental modality no additional payments are made upon successful grade completion.

Medellin modality: Unlike all other major cities, Medellin and Cali operate the rural version of Familias en Accion. In the rural version, eligible households with students in grades 6 through 11 receive a subsidy of $\$ 19 /$ month, and, in contrast to the savings and incremental modalities, eligible households with elementary school students do receive a subsidy of $\$ 9.5 /$ month.

In all three modalities of FAU, families receive transfers through a dedicated savings account and can withdraw the money using an ATM card. These transfer amounts are substantial. For example, a fully compliant household with two school-aged children-one starting in grade 6 and one starting in grade 9-receives in the incremental modality a total of $\$ 564$ in one year $(\$ 19 \times 12+28 \times 12)$. At the time FAU began, this corresponded to 14 percent of GDP per capita and to 27 percent of the annual income that FAU eligible households report in the SISBEN 2005 census of the poor.

\section{Data sources, sample restrictions and descriptive statistics}

\section{a. Data sources}

We use three data sources in our analyses: the ECV 2010 survey, the SISBEN 2005 census of the poor, and the 2007 CNPD baseline survey.

ECV 2010 survey: Our main data source is the 2010 Colombian National Quality of Life Survey (ECV for its original acronym in Spanish). ${ }^{9}$ The ECV is a nationally representative survey of the population of Colombia. The Colombian National Administrative Department of Statistics (DANE for its acronym in Spanish) modeled the ECV survey after the World Bank's Living Standards Measurement Survey (LSMS). ${ }^{10}$ DANE administered the ECV survey in 1993, 1997, 2003, 2007, 2008 and every year since 2010.

The official government SISBEN scores are not included in the ECV surveys. We obtained confidential access from Colombia's Central Bank (Banco de la República de

\footnotetext{
${ }^{8}$ The savings and incremental modality transfer comparable monetary amounts (in net present value) to families that fulfill all conditions under a low-inflation scenario.

${ }^{9}$ Encuesta de Calidad de Vida, publicly available from http://www.dane.gov.co/index.php/esp/estadisticassociales/calidad-de-vida-ecv/87-sociales/calidad-de-vida/3885-encuesta-de-calidad-de-vida-2010.

${ }^{10}$ For details see http://go.worldbank.org/WKOXNZV3X0.
} 
Colombia) to the formula used by the government to generate SISBEN scores (from the SISBEN 2005 census of the poor). We employ this formula to generate SISBEN scores in the ECV 2010 survey. Our analysis is limited to the ECV 2010 since 2010 is the only year for which all the questions necessary for generating the SISBEN score are available, and for which they are identical to those used by the government. ${ }^{11}$

The ECV 2010 survey includes multiple subjective wellbeing questions as well as monetary measures of wellbeing such as expenditures and income data. ${ }^{12}$ The subjective wellbeing questions - the key outcomes in our analyses - ask respondents to rate their subjective satisfaction with various domains that include: life in general, education, control over one's life, dignity, community, ability to help others, food, dwelling, income, health, work, level of security, friends, and family. The survey asks: "how satisfied or unsatisfied are you with the following..." Response options are categorical: very dissatisfied (1), unsatisfied (2), satisfied (3) and very satisfied (4). ${ }^{13}$ Appendix A describes in detail the construction of variables used in the analysis.

SISBEN 2005 census of the poor: The Colombian government uses the SISBEN census of the poor to determine eligibility for FAU and a host of other government assistance programs. The census provides the exact SISBEN score as used by the government. To capture the entire population of Colombia's poor, the government administers the SISBEN census of the poor to all households residing in poor neighborhoods. Households have an incentive to be surveyed and they can request a survey if not initially canvassed. The SISBEN census of the poor was collected between 2005 and 2006 and contains information on about 20 million individuals, roughly 50 percent of Colombia's population. For comparison, the percentage of the population living below the national poverty line at the time of the SISBEN 2005 census of the poor was about 40 percent (World Bank, 2016).

\footnotetext{
${ }^{11}$ The 2008 ECV survey also contains subjective wellbeing questions, but does not contain all the variables necessary to generate SISBEN scores. Further, the SISBEN score formula changed after 2010 so that later waves of the ECV can also not be used. For these reasons our analyses are limited to the ECV 2010.

${ }^{12}$ Some questions in the ECV 2010 survey refer to the household (e.g., physical characteristics of the household and household expenditures), others to the full roster of individuals in the household (income and educational attainment) and others to the survey respondent only (e.g., subjective wellbeing questions). Note that the survey respondent may not be the head of the household.

${ }^{13}$ This question is an evaluative subjective wellbeing measure where respondents are asked to consider their life as a whole, weighing what aspects of their life are important to their wellbeing, before choosing a response category that most closely reflects their evaluation. Evaluative measures of wellbeing are strongly correlated with objective measures of life circumstances (World Happiness Report, 2012).
} 
2007 CNPD baseline survey: Baseline data for the evaluation of the FAU program, commissioned by Colombia's National Planning Department, was collected in 2007 and contains the actual SISBEN scores from the SISBEN 2005 census of the poor. The 2007 CNPD baseline survey oversampled households just above and just below the FAU eligibility cutoff (Appendix Figure C-1). Because of this oversampling the 2007 CNPD baseline survey allows for an accurate assessment of the extent to which actual program participation is matched to having a score below the FAU SISBEN cutoff of 11.

\section{b. Sample restrictions}

We impose various restrictions on the ECV 2010 raw dataset. First, we restrict the sample to the 14 participating FAU cities, using survey indicators for each of the 14 major Colombian cities. We then restrict the sample to households with children age 18 and younger, as this is a key FAU program eligibility criterion. Finally, we restrict the data to households with (estimated) SISBEN scores between 0 and 22 points (recall that the FAU eligibility cutoff is 11 points). The final analysis sample contains 668 households.

As noted earlier, FAU operated through three payment modalities - a savings modality, an incremental modality, and the Medellin modality. Due to the already small number of households around the SISBEN cutoff in the final analysis sample, we do not analyze the FAU payment modalities separately.

c. Descriptive statistics of ECV 2010 households and comparison with the SISBEN 2005 census of the poor

Panels A, B, C and D of Table 1 compare characteristics of households located in the 14 FAU cities in the SISBEN 2005 census of the poor with those in the ECV 2010 survey. Panel A does not impose any restrictions on the household. Panel B restricts both data sources to households with children of eligible age (under age 18). Panel C further restricts both samples to include only households with SISBEN scores below 22 (actual score in the SISBEN census, estimated score in ECV 2010 survey). Note that Panel C reflects the restrictions imposed in our analyses. Finally, panel D further restricts to households with SISBEN scores below the eligibility cutoff of 11 points. In all four panels, the SISBEN census' households appear more socioeconomically disadvantaged than those in the ECV 2010 survey. 
There are three main reasons for observed differences. First, the sampling frame for both data sources differs: the SISBEN census of the poor targets the poorest households whereas the ECV 2010 is a nationally representative survey.

Second, part of the difference may stem from actual improvements in living conditions between the collection of the SISBEN 2005 census of the poor and the ECV 2010 survey due to economic growth or changes in government policy between 2005 and 2010. Observed differences in average household income in Panels $\mathrm{C}$ and $\mathrm{D}$ of Table 1 imply a rate of income growth of 26 and 24 percent per year, respectively. Gross national income during that same period grew by 3.2 percent per year, suggesting that general improvements in living conditions play a minimal role.

Third, there are incentives to underreport in the SISBEN census of the poor (e.g., Camacho and Conover, 2011) but not in the ECV 2010 survey. SISBEN scores determine

eligibility for all government social programs. Households have incentives to underreport whenever possible. For the SISBEN census of the poor, enumerators visit each household and physically inspect the dwelling. Information on educational attainment, formal employment and income, however, is entirely based on self-reports. Given the desirability of being eligible for as many government welfare programs as possible, households may underreport some of these nonverifiable characteristics. Income, a measure that appears to be underreported, is not included in the computation of SISBEN scores yet families do not necessarily know this. Determining program participation is therefore not affected by the extent to which families underreport income. Note further that the average SISBEN score in panel D is very similar for the SISBEN 2005 census and the ECV 2010 survey, suggesting SISBEN scores are relatively robust to manipulation.

\section{Research design}

As discussed, a limitation of the ECV 2010 survey is that the variables used to calculate SISBEN scores are measured in 2010, three years after the start of FAU (2007) and five years after the SISBEN scores were assigned (2005 census of the poor). The 2010 SISBEN scores of those who are eligible could have been affected by FAU program participation, potentially improving the scores of participating households. Individual, household, local and national level changes in economic conditions and fortune may also change SISBEN scores up or down. 
Differences in the sampling frame, with the SISBEN census targeting the poorest households may also lead to differences with ECV 2010 estimated SISBEN scores. Last, there is an incentive to underreport in the SISBEN 2005 census of the poor since the census is used to determine eligibility for FAU as well as other government assistance programs.

We hypothesize that underreporting in the SISBEN census and general improvements in living conditions would shift the mean of the cut-off score (estimated from ECV 2010 survey data) upward, while individual and household level changes in economic conditions and fortune would reduce (blur) the sharpness in the observed drop between FAU participation and the estimated SISBEN score around the cutoff. Some households initially above the cutoff and not participating end up below the cutoff (reducing the rate of participation below the cutoff) while other households initially below the cutoff and participating end up above the cutoff (increasing the rate of participation above the cutoff). This would blur the discontinuity in program participation at the cutoff.

In this section we validate the research design and discuss our approach to dealing with measurement error in the ECV 2010 survey's estimated SISBEN scores.

\section{a. First stage: program participation around the FAU eligibility cutoff}

To validate the research design we need to establish that there is a sharp drop in program participation at the eligibility cutoff shortly after the program was implemented. We use the 2007 CNPD baseline survey to determine the functional relationship between program participation at baseline and the actual SISBEN scores, since both are available in the 2007 CNPD baseline survey.

Panel A of Figure 1 plots the FAU participation rates in the 2007 CNPD baseline survey as a function of the distance in the SISBEN score from the FAU eligibility cutoff (dotted vertical line). Each data point represents the program participation mean in a one-unit SISBEN score interval. We also include the 90 percent confidence interval for each mean and non-parametric (lowess) fits to the data, separately estimated for each side of the cutoff. Recall that this survey significantly oversampled near the FAU eligibility cutoff, explaining the greater accuracy of measurement near the cutoff. There is a significant discontinuity (a strong drop) in FAU participation at the FAU eligibility cutoff. Compliance with the FAU assignment rule, however, is imperfect. For instance, about 65 to 70 percent of eligible households (below the cutoff) participate in the FAU program. Similarly, while immediately above the cutoff there is no 
evidence of significant program participation (at most a few percent), further out some 15 to 20 percent of ineligible households participate in FAU. At the cutoff, the difference in participation rates is 60 to 65 percentage points.

In the absence of measurement error in estimated ECV 2010 SISBEN scores, we would expect to see a similarly sharp drop in participation at the FAU eligibility cutoff in the ECV 2010 data. As noted above, however, underreporting in the SISBEN census and general improvements in living conditions would shift the mean of the cut-off score upward, while individual and household level changes in economic conditions and fortune would reduce the sharpness in the observed drop between FAU participation and the estimated SISBEN score around the cutoff.

The ECV 2010 asks respondents whether they currently receive subsidies from the FAU program. We use this question to demonstrate the existence of a drop in the probability of receiving FAU subsidies around the estimated SISBEN eligibility cut-off score. Panel B of Figure 1 shows FAU participation as reported in the ECV 2010 as a function of estimated (not actual) SISBEN scores from ECV 2010 data. The vertical dashed lines represent a "doughnut hole" and we will return to this later. Average FAU participation rates for eligible and ineligible households in ECV 2010 are remarkably similar to those in the 2007 baseline data. Specifically, about 60 percent of eligible households (below the cutoff) participate in FAU and about 15 to 20 percent of ineligible households (above the cutoff) participate in FAU (note that participation drops down further away from the cutoff). However, as expected from SISBEN scores generated with error, Panel B of Figure 1 does not show the steep fall in program participation above the cutoff as was documented in Panel A for the 2007 CNPD baseline survey data.

To circumvent the issue of measurement error in the running variable (generated SISBEN scores) around the FAU eligibility cutoff, we use a "doughnut hole" regression discontinuity (RD) approach. In the "doughnut hole" RD approach, households with estimated SISBEN scores inside the doughnut hole are eliminated from the analysis. Traditionally, the "doughnut hole" $\mathrm{RD}$ approach has been used to deal with strategic manipulation of one's position relative to the cutoff, inducing reverse-causality bias (e.g., Hoxby and Bulman, 2015). To our knowledge, we are the first to use this approach to deal with measurement error in the running variable.

To date, no econometric theory exists to optimally estimate doughnut holes. Intuitively, however, one would want the smallest possible hole so as to maximize comparability across the cutoff and to maximize statistical power (Hoxby and Bulman, 2015). In the absence of such 
theory, we propose, as follows, a simple post-hoc cross-validation approach to choose the size of the doughnut hole in our analysis.

Given that we know the first-stage functional relationship between actual SISBEN scores and FAU participation from the 2007 CNPD baseline data, our approach consists of choosing the smallest doughnut hole that produces a similar first-stage in the ECV 2010 survey data. Our preferred doughnut hole drops observations between -1 and 2 points of the estimated SISBEN score. As Panel B of Figure 1 shows, the $[-1,2]$ doughnut hole produces a first-stage functional relationship that resembles the actual program participation functional relationship at the cutoff documented in Panel A of Figure 1. ${ }^{14}$

Table 2 presents regression analogs to Figure 1. In the 2007 CNDP baseline data, households just below the eligibility threshold have a seventy-percentage point higher probability of FAU participation relative to households just above (local control mean is 3 percent). This first stage estimate is consistent across various bandwidths (Panel A, Table 2). The first stage F-stat for the program eligibility indicator in the 2007 CNDP baseline data exceeds two thousand in all specifications.

Panels B and C of Table 2 show linear and non-linear (probit), respectively, first-stage results in the ECV 2010 survey data using the [-1,2] doughnut hole around the cutoff point. In the ECV 2010 data, households just below the eligibility threshold have a roughly fortypercentage point higher probability of FAU participation relative to households just above. The difference in the probability of FAU participation induced by the cutoff rule is smaller in the 2010 ECV survey than in the 2007 CNPD baseline administrative data. However, program participation among eligible households is similar in both datasets. The point-estimate difference at the cutoff is due to a larger fraction of local non-eligible households participating in FAU in the 2010 ECV survey data (16.5 percent) than in the 2007 baseline administrative data (3 percent). The first stage F-stat for the program eligibility indicator in the in the ECV 2010 survey exceeds ten in most specifications. ${ }^{15}$

\footnotetext{
${ }^{14}$ Note that, as with the cross-validation approach to choosing the bandwidth for RD estimation (Imbens and Lemieux, 2008), there is no restriction imposed on the doughnut hole being symmetrical around the cutoff. The [$1,2]$ doughnut hole is also consistent with the notion that general improvements in living conditions shift the mean of the cutoff score upward.

${ }^{15}$ An alternative fuzzy RD empirical approach would be to use the first-stage moments from the 2007 CNPD baseline administrative data and the reduced-form moments from the ECV 2010 survey data. This approach would be akin to a two-sample instrumental variables estimator (see, for example, Angrist and Krueger 1992, 1995; Dee and Evans 1999). While the source of variation and resulting reduced form estimates are the same, fuzzy RD
} 
b. Covariate continuity and the density of SISBEN scores around the FAU eligibility cutoff

We provide evidence of covariate continuity from two alternative data sources: the SISBEN 2005 census data - which determined program eligibility at baseline - and the ECV 2010 survey data. As noted, variables measured in the SISBEN 2005 census clearly represent pre-treatment characteristics, while variables measured in the ECV 2010 data may have been affected by FAU participation or other factors. For this reason, we examine covariate continuity in the ECV data for variables that are potentially less likely to be influenced by program participation for three years, which include dwelling and infrastructure characteristics, educational attainment of the head and partner and average children age.

We cannot reject continuity at the cutoff for any of these characteristics in the SISBEN 2005 census data (Left-hand Panels of Figure B-1 in Appendix B). In the ECV 2010 survey we cannot reject continuity at the cutoff for most variables except, for some bandwidths, whether the partner of the household head has completed secondary education and dormitories per person (Right-hand Panels of Figure B-1). In addition to evidence on covariate continuity, there is a high degree of similarity in the functional-form relationship between actual SISBEN scores and household characteristics in the SISBEN 2005 census, and between estimated SISBEN scores and characteristics in the ECV 2010 survey (Figure B-1). The high degree of comparability between the SISBEN census and the survey in the functional-form relationship between SISBEN scores and household characteristics, selected such that they are not likely affected by FAU, provides further credence to the research design.

An additional test for the validity of the RD design is the absence of bunching in the density of SISBEN scores just below the FAU eligibility cutoff. We present results from this test in Figure 2. Actual SISBEN scores in the SISBEN 2005 census exhibit a bimodal distribution, the density is continuous at the cutoff, and there are fewer households below the cutoff than there are above the cutoff (Panel A, Figure 2). The absence of bunching below the cutoff is consistent with households not being able to manipulate their position relative to the cutoff in response to introduction of FAU - unsurprising since the government collected the SISBEN 2005 data roughly two years before FAU was introduced. Importantly, the distribution of generated 
SISBEN scores in the ECV 2010 survey also shows absence of bunching below the cutoff with a lower density below the cutoff compared to above the cutoff (Panel B, Figure 2). ${ }^{16}$ The absence of evidence of manipulation in the ECV 2010 survey is reassuring as it is the main dataset used in our analyses. The covariate continuity and density tests in the SISBEN 2005 and ECV 2010 data thus help validate the RD research design. Further, the doughnut hole design reduces the role of manipulation should it still exist.

\section{c. Fuzzy RD estimation strategy}

As shown above in subsection (b), not all eligible households below the SISBEN cutoff participated in FAU, while some households above the SISBEN cutoff did. Because of the households' imperfect compliance and measurement error in generated SISBEN scores in the ECV 2010 data we use a fuzzy RD design with a doughnut hole. In the doughnut hole fuzzy RD design, we omit households within estimated SISBEN scores between -1 and 2 SISBEN points from the eleven-point eligibility cutoff. Specifically, the first-stage equation is:

1. $F A U_{i}=\gamma+\delta W_{i}+\rho X_{i}+\lambda W_{i} * X_{i}+\eta_{d}+v_{i}$, where $F A U_{i}$ equals one if household $i$ reports participating in FAU in the ECV 2010 data, $W_{i}=1$ if $X_{i} \leq c^{\text {Lower }}$ and equals zero otherwise, $W_{i}=0$ if $X_{i} \leq c^{\text {Upper }}, X_{i}$ is the distance in the generated SISBEN score for household $i$ from the doughnut boundary, $\eta_{d}$ are program city dummies to capture the fact that eligibility is tied to residence and that there is variation in FAU program characteristics across cities, and $v_{i}$ is an estimation error term. Estimates of $\delta$ measure the estimated difference in the probability of receiving FAU at the boundary cutoff as a function of generated SISBEN scores and correspond to those reported in Figure 1 and Panels B and C of Table 2.

The second-stage equation is:

2. $Y_{i}=\alpha+\tau \widehat{F A}_{i}+\beta X_{i}+\xi \widehat{F A}_{i} * X_{i}+\mu_{d}+\varepsilon_{i}$, where $Y_{i}$ is the outcome variable of interest for household $i, \widehat{F A}_{i}$ is the predicted probability of FAU participation for household $i$ from the first-stage model, $X_{i}$ is defined as before, $\mu_{d}$ are program city dummies and $\varepsilon_{i}$ is the error term of the second-stage equation.

\footnotetext{
${ }^{16}$ Appendix Figure C-1 shows the density of SISBEN scores among participants in the 2007 baseline survey. The density is continuous at the cutoff. The mass around the cutoff is the result of a sampling frame that oversampled households near the FAU eligibility cutoff.
} 
In our results, we report fuzzy RD estimates for bandwidths 9, 8, 7, 6 and 5 SISBEN points away from the doughnut boundary cutoff. For binary outcomes $Y_{i}$, we employ bivariate probit models (Angrist and Pischke 2009; Chiburis et al. 2012). We assess statistical significance relative to p-values adjusted for multiple hypotheses testing using the Benjamini-Hochberg (1995) procedure.

\section{Results}

This section contains three subsections. In subsection (a) we present evidence on impacts of FAU participation on income, expenditure and formal employment. In subsection (b) we present evidence of impacts on self-reported health, health service utilization and school enrollment of children. In subsection (c) we present evidence of impacts on subjective wellbeing, including domain-specific satisfaction, life satisfaction, and happiness.

a. Impacts of FAU participation on household monthly income, expenditure and formal employment

Three years after the introduction of FAU, eligible households just below the boundary cutoff report having higher monthly household income than households just above the eligibility cutoff (Panel a, Figure 3). Accounting for the fraction of eligible FAU non-participants below the cutoff as well as for the fraction of participants above the cutoff in the fuzzy RD regression framework of equations 1 and 2 above, yields an implied local estimate of FAU participation that ranges from $\$ 525 /$ month to $\$ 643 /$ month for bandwidths of 5 to 7 SISBEN points (Row 1, Table 3). These estimates use a conservative linear fit with a uniform kernel (unlike Figure 3, which shows flexible lowess fits that may be more sensitive to observations near the doughnut boundary). For these smaller bandwidths, estimates of FAU participation are statistically significant, even after accounting for multiple testing (at the 5 percent level for the 5-SISBEN point bandwidth, and 10 percent level for the 6- and 7-point bandwidth). For bandwidths 8 and 9 , the estimates are positive but smaller, $\$ 388$ and $\$ 316$, respectively, and not statistically significant.

Estimated effects of FAU participation on monthly income are large in magnitude. Depending on the bandwidth, they represent a 46 to 95 percent increase relative to average income of $\$ 607 /$ month for local control households. Estimated income increases that result from FAU participation at the margin are substantially more than would be expected solely on the 
basis of FAU income subsidies. As explained earlier, a fully compliant household with two school-aged children may receive in the FAU incremental modality a total of $\$ 564$ year, or a factor of about ten less.

The large effect of FAU participation on household income may be explained by FAU participation also improving formal labor market outcomes of the household head and his/her partner among marginal households (Panels $\mathrm{c}$ and d, Figure 3). Accounting for non-compliance at the eligibility boundary, the implied local estimate of FAU participation on the probability of formal employment of the household head ranges from 43 to 66 statistically significant percentage points depending on bandwidth choice (Row 3, Table 3). Similarly, the implied local estimate of FAU participation on the probability of formal employment of the partner of the household head ranges from 15 to 27 statistically significant percentage points depending on bandwidth choice (Row 4, Table 3).

For marginal households, income increases that result from FAU participation-and improved labor market opportunities - map almost one to one to changes in consumption. Monthly expenditures increase for eligible households just below the boundary cutoff relative to those above (Panel b, Figure 3). Accounting for non-compliance at the eligibility boundary, the implied local estimate of FAU participation on household expenditures ranges from \$386/month to $\$ 566 /$ month depending on bandwidth (Row 2, Table 3). For local control households, monthly expenditures three years after the introduction of FAU imply a marginal propensity to consume of about 63 percent of income $(\$ 384 / \$ 607$, Table 3). In contrast, the marginal propensity to consume out of the additional dollar due to FAU participation (and improved labor market opportunities for the head and partner) ranges from 88 percent $(\$ 566.3 / 643.3$, bandwidth of seven SISBEN points, Table 3) to 124 percent $(\$ 480.0 / \$ 388.1$, bandwidth of nine SISBEN points, Table 3).

Estimated effects of FAU participation on income, expenditure and formal employment outcomes are consistent across alternative definitions of the doughnut hole around the eligibility cutoff (Appendix Tables $\mathrm{C} 1$ and $\mathrm{C} 4$ ). In sum, our evidence suggests that three years into the program, households have higher consumption due to a combination of additional income from the program's cash subsidies and from improved formal labor market opportunities for the household head and partner. 
A simple back-of-the-envelope calculation illustrates how the program may have achieved these outcomes at a reduced cost to taxpayers. A fully compliant participant household with two school-aged children — one starting in grade 6 and one starting in grade 9-may receive in FAU's incremental modality a total of $\$ 564$ in one year $(\$ 19 \times 12+28 \times 12)$ or $\$ 47 /$ month. Transfer amounts are about 90 percent of total program costs, with the remaining 10 percent being administrative costs (Garcia and Saavedra 2017). Hence, to distribute $\$ 1$ in transfers, the government needs to spend about \$1.1. This implies that for a fully compliant household, a transfer of $\$ 47 /$ month costs the government about $\$ 52$, not accounting for the deadweight loss of taxation. In Colombia, employee payroll contributions are 10 percent of income. Conservatively assuming no increased VAT tax collection through consumption and an increase in household income coming entirely through increased formal employment, increased payroll taxes among participants at the margin are between \$32-\$64/month, depending on the bandwidth of choice used in estimating the impacts on monthly household income $(0.1 \mathrm{x}$ impact of the program on monthly household income of participants, Row 1, Table 3). Therefore, our point estimates imply that three years into the program, the cost to taxpayers may be between 40 percent and -23 percent of total program costs.

b. Impacts of FAU participation on self-reported health, health-service utilization and school enrollment of children

Graphical evidence suggests that FAU eligibility improves self-reported health for marginal households (Panel a, Figure 4). Accounting for non-compliance at the eligibility boundary, estimates of FAU participation are positive for all bandwidths (Row 1, Table 4). However, once we adjust critical values for multiple testing, we only reject at the 10-percent level and for the largest 9-SISBEN point bandwidth that FAU participation does not affect selfreported health of household members. We do not find evidence that FAU participation affected the likelihood of paid medical consultations (Panel b, Figure 4 and Row 2, Table 4) or the likelihood of illness not requiring hospitalization (Panel c, Figure 4 and Row 3, Table 4).

Eligibility for and participation in the FAU program does not affect school enrollment outcomes for marginal households (Panel d, Figure 4 and Row 4, Table 4). This result is consistent with survey evidence from Nuñez et al. (2011) who show that after four years of program participation, FAU did not affect school enrollment outcomes of participants. However, it is inconsistent with other results from Nuñez et al. (2011), based on administrative data, 
suggesting that three to four years into the program, FAU participation improved educational outcomes such as grade progression and the probability of completing grade 9. Our point estimates and confidence intervals are large, however. Therefore, we cannot make any definitive statements with regards to the impact of FAU participation on the fraction of age-eligible children in the household who are enrolled in school.

Appendix Tables C2 and C5 show results for self-reported health, health service utilization and school enrollment under alternative definitions of the doughnut boundary. Results are robust to these alternative choices.

c. Impacts of FAU participation on subjective wellbeing on domain satisfaction, overall life satisfaction, and happiness.

We estimate the effect of FAU participation on satisfaction with life, happiness, and all domain satisfaction questions included in the EVC 2010. The head of the household was the only person to be asked these questions, so we lack information on the perceptions of other members of the household. Domain satisfaction variables included in the EVC 2010 are satisfaction with: income, work, food, level of control over one's life, dwelling, ability to help others, health, education, community, level of security, and friends.

Figure 5 shows graphical evidence of the effect of FAU eligibility on wellbeing variables. Table 5 shows results of FAU participation accounting for the fraction of eligible FAU nonparticipants below the cutoff as well as for the fraction of participants above the cutoff. We find some evidence that FAU participation increases overall satisfaction with life and happiness, as reported by the household head. However, these conclusions are sensitive to bandwidth choice (Rows 1 and 2, Table 5).

We do not find evidence that FAU increased domain satisfaction with income or with work for households on the margin of eligibility (Rows 3 and 4, Table 5). The lack of improved satisfaction on these two domains stands in contrast with the large effects of FAU participation on income and formal employment outcomes three years into the program documented earlier.

We find consistent evidence that marginal households participating in the FAU program are more satisfied with food (Row 5, Table 5). Satisfaction with food, three years into the program, may be a consequence of increased household expenditures, as documented earlier in Table 3. Food may be a domain of life's circumstances in which income increases lead to permanent changes in evaluative wellbeing. 
Participation may also lead to increased satisfaction with the level of control over one's life and to increased satisfaction with one's dwelling (Rows 6 and 7, Table 5). However, in these two domains, results are sensitive to RD bandwidth choice.

Participation in FAU does not improve marginal household's satisfaction with health or education (Rows 9 and 10, Table 5). This result may be consistent with FAU not improving selfreported health, health utilization or school enrollment outcomes for marginal participants, as documented earlier. We also do not find evidence that three years into the program, FAU participation increases marginal household's satisfaction with their ability to help others (Row 8), their community (Row 11), their level of security (Row 12) or their friends (Row 13, Table $5)$.

Due to the small sample size in the ECV 2010 some of the null results on the domain satisfaction variables could simply be due to lack of statistical power given variability in the outcome variables. To test if there is an overall improvement in satisfaction with domains in general, we employ a variance weighted mean meta-analysis approach to test for an average aggregated effect of domain satisfaction (Cooper et al. 2009).

Rows 14 and 15 of Table 5 show effects of FAU participation on the precision-weighted overall satisfaction and happiness variables. Under this precision-weighted technique, we find evidence consistent with FAU participation improving overall life satisfaction and happiness three years into the program. For the average effect, over eleven domain variables, estimates of FAU participation are positive and significant for all bandwidths with the exception of the smallest 5-SISBEN point bandwidth. For the average effect of overall satisfaction with life and happiness we find positive effects for all bandwidths with the exception of the 5-point bandwidth, and statistical significance for the 6- and 7-SISBEN point bandwidth. These results are robust to alternative definitions of the doughnut boundary (Appendix Tables C3 and C6).

\section{Conclusion}

In the context of a conditional cash transfer program in Colombia, this paper documents how anti-poverty programs may make participants relatively wealthier, happier and more selfsufficient at a reduced cost to taxpayers. These results cast doubt on the notion that welfare programs always generate work disincentives for participants. 
Our results suggest that three years into the program household income increased by tenfold the amount of the government cash-transfer, likely because of gains in formal employment. This finding highlights how relatively small subsidies, further offset by additional government tax receipt, generate substantial benefits to poor families. A simple back-of envelope calculation suggests that - for marginal applicants - the actual cost to taxpayers is about 40 percent of actual program costs, and may even be zero or negative under alternative regression models.

Greater expenditures, particularly on food, appear to have led to improvements in subjective wellbeing, suggesting that one way in which anti-poverty programs improve household wealth, happiness and self-sufficiency is through improved choice sets, such as opportunities for more plentiful and better quality nutrition.

Our findings provide some support for the notion that people's reported satisfaction with life could be a worthy goal of policy making. In our setting, subjective self-reports respond to policy changes, these responses are relatively long lasting and they are associated with important improvements in objective measures such as income, expenditures and participation in the workforce. 


\section{References}

Angrist, Joshua D., and Alan Krueger, "The Effect of Age at School Entry on Educational Attainment: An Application of Instrumental Variables with Moments from Two Samples," Journal of the American Statistical Association 87 (1992): 328-336.

Angrist, Joshua D., and Alan Krueger, "Split Sample Instrumental Variables Estimates of the Return to Schooling," Journal of Business and Economic Statistics 13 (1995): 225-235.

Angrist, Joshua D., and Jorn-Steffen Pischke, 'Mostly Harmless Econometrics: An Empiricists Companion', Princeton, NJ: Princeton University Press, (2009).

Baird, Sarah, Jacobus de Hoop, and Berk Özler, "Income Shocks and Adolescent Mental Health." Journal of Human Resources 48.2 (2013): 370-403.

Banerjee, Abhijit, Rema Hanna, Gabriel Kreindler and Benjamin Olken, "Debunking the Stereotype of the Lazy Welfare Recipient: Evidence from Cash Transfer Programs" mimeo MIT (2016).

Barrera-Osorio, Felipe, Marianne Bertrand, Leigh Linden, and Francisco Perez-Calle, "Improving the Design of Conditional Transfer Programs: Evidence from a Randomized Education Experiment in Colombia." American Economic Journal: Applied Economics 3.2 (2011): 167-95.

Benjamini, Yoav and Yosef Hochberg, "Controlling the False Discovery Rate: A Practical and Powerful Approach to Multiple Testing," Journal of the Royal Statistical Society 57.1 (1995): 289-300.

Bettinger, Eric, Michael Kremer, Maurice Kugler, Carlos Medina, Christian Posso and Juan E. Saavedra, "Can Educational Voucher Programs Pay for Themselves?" mimeo, Harvard University, (2017).

Boarini, Romina, Conal Smith, Margherita Comola, Robert Manchin, and Femke de Keulenaer, What Makes for a Better Life?: The Determinants of Subjective Well-being in OECD Countries Evidence from the Gallup World Poll., 2012. http://dx.doi.org/10.1787/5k9b91tjm937-en

Boyd-Swan, Casey, Chris M. Herbst, John Ifcher, and Homa Zarghamee, "The Earned Income Tax Credit, Mental Health, and Happiness." Journal of Economic Behavior and Organization 126 (2016): 18-38.

Camacho, Adriana, and Emily Conover, "Manipulation of Social Program Eligibility." American Economic Journal: Economic Policy 3.2 (2011): 41-65.

Carr, Ewan, and Heejung Chung, "Employment Insecurity and Life Satisfaction: The Moderating Influence of Labour Market Policies Across Europe." Journal of European Social Policy 24.4 (2014): 383-99. 
Cattaneo, Matias D., Sebastian Galiani, Paul J. Gertler, Sebastian Martinez, and Rocio Titiunik, "Housing, Health, and Happiness." American Economic Journal: Economic Policy 1.1 (2009): 75-105.

Chiburis, Richard C., Jishnu Das, and Michael Lokshin, “A practical comparison of the bivariate probit and linear IV estimators.” Economics Letters 117(2012): 762-766.

Cooper, Harris M., Larry V. Hedges, and Jeff C. Valentine, 'The Handbook of Research Synthesis and Meta-Analysis', 2nd ed., New York, Russell Sage Foundation, (2009).

Deaton, Angus, "Income, Health and Well-Being Around the World: Evidence from the Gallup World Poll," Journal of Economic Perspectives 22.2 (2008): 53-72.

Dee, Thomas and William Evans, "State Alcohol Policies, Teen Drinking and Traffic Fatalities" , Journal of Public Economics, 72 (1999): 289-315.

Devoto, Florencia, Esther Duflo, Pascaline Dupas, William Parienté, and Vincent Pons, "Happiness on Tap: Piped Water Adoption in Urban Morocco." American Economic Journal: Economic Policy 4.4 (2012): 68-99.

Di Tella, Rafael, Robert J. MacCulloch, and Andrew J. Oswald, "The Macroeconomics of Happiness." The Review of Economics and Statistics 85.4 (2003): 809-27.

Di Tella, Rafael, John Haisken-De New, and Robert MacCulloch, "Happiness adaptation to income and to status in an individual panel," Journal of Economic Behavior \& Organization 76.3 (2010): 834-852.

Easterlin, R.A. "Well - Being, Front and Center: A Note on the Sarkozy Report." Population and Development Review (2010a): 36(1), pp.119-124.

Finkelstein, Amy, Sarah Taubman, Bill Wright, Mira Bernstein, Jonathan Gruber, Joseph P. Newhouse, Heidi Allen, and Katherine Baicker, "The Oregon Health Insurance Experiment: Evidence from the First Year." Quarterly Journal of Economics 127.3 (2012): 1057-106.

Garcia, Sandra and Juan E. Saavedra, "Educational Impacts and Cost-Effectiveness of Conditional Cash Transfer Programs in Developing Countries: A Meta-Analysis." Review of Educational Research July (2017): 1-45.

Gardner, Jonathan, and Andrew J. Oswald, "Money and Mental Wellbeing: A Longitudinal Study of Medium-Sized Lottery Wins." Journal of Health Economics 26.1 (2007): 49-60.

Haushofer, Johannes, and Jeremy Shapiro, "The Short-Term Impact of Unconditional Cash Transfers to the Poor: Evidence from Kenya." Quarterly Journal of Economics, forthcoming, 2016. 
World Happiness Report 2012, Helliwell, John F., Richard Layard, and Jeffery Sachs, ed. (New York: Sustainable Development Solutions Network).

Helliwell, John F., and Haifang Hwang, "How's Your Government? International Evidence Linking Good Government and Well-being." British Journal of Political Science 38.4 (2008): 595-619. Web.

Hoxby, Caroline and Bulman, George. "The effects of the tax deduction for post-secondary tuition: Implications for structuring tax-based aid.” NBERWorking Paper no. 21554, 2015.

Imbens, Guido W., and Thomas Lemieux, "Regression Discontinuity Designs: A Guide to Practice." Journal of Econometrics 142.2 (2008): 615-35.

Inter-American Development Bank and World Bank, "Solicitud Estándar de Propuestas para la Evaluación de Impacto de la Expansión Urbana del Programa Familias en Acción." Solicitud de Propuestas SP Crédito BID No. 1947-OC-CO-1, República de Colombia, 2011.

Kahneman, Daniel, Alan B. Krueger, David Schkade, Norbert Schwarz and Arthur Stone, "Would you be Happier if you were Richer? A Focusing Illusion," Science 312.5782 (2006): 1908-10.

Kuhn, Peter, Peter Kooreman, Adriaan Soetevent, and Arie Kapteyn, "The Effects of Lottery Prizes on Winners and their Neighbors: Evidence from the Dutch Postcode Lottery." The American Economic Review 101.5 (2011): 2226-47.

Layard, Richard, Happiness: Lessons from a New Science, (2005). New York: Penguin Press.

Luttmer, Erzo, "Neighbors as Negatives: Relative Earnings and Well-Being," Quarterly Journal of Economics 120.3 (2005): 963-1002.

Murray, Charles, Losing Ground: American Social Policy 1950-1980, (1984). New York: Basic Books.

Nuñez, Jairo et al. "Evaluación del Programa Familias en Acción en Grandes Centros Urbanos: Informe Final.” Report, Centro Nacional de Consultoria, Colombia, 2011.

Pacek, Alexander C., and Benjamin Radcliff, "Welfare Policy and Subjective Well-being Across Nations: An Individual-Level Assessment." Social Indicators Research 89.1 (2008a): 179-91.

Pacek, Alexander, and Benjamin Radcliff, "Assessing the Welfare State: The Politics of Happiness." Perspectives on Politics 6.2 (2008b): 267-77.

Rothstein, Bo, "Happiness and the Welfare State." Social Research 77.2 (2010): 441-68. 
Report by the Commission on the Measurement of Economic Performance and Social Progress, 2009, Stiglitz, Joseph E., Amartya Sen, and Jean-Paul Fitoussi; available at http://www.stiglitzsen-fitoussi.fr/documents/ rapport_anglais.pdf.

Veenhoven, Ruut, “Is Happiness Relative?” Social Indicators Research 24.1 (1991): 1-34.

World Bank. 2016. World Development Indicators, available at data.worldbank.org/indicators.

Wulfgramm, Melike, "Life Satisfaction Effects of Unemployment in Europe: The Moderating Influence of Labour Market Policy." Journal of European Social Policy 24.3 (2014): 258-72. 
Table 1: Household Characteristics, 2005 Census of the Poor and ECV 2010 Survey

\begin{tabular}{|c|c|c|c|c|c|c|c|c|}
\hline \multirow[b]{2}{*}{ Household member characteristics } & \multicolumn{2}{|c|}{$\begin{array}{c}\text { Panel A: Program Cities, all } \\
\text { Households }\end{array}$} & \multicolumn{2}{|c|}{$\begin{array}{l}\text { Panel B: Program Cities, all } \\
\text { Households with Children }\end{array}$} & \multicolumn{2}{|c|}{$\begin{array}{c}\text { Panel C: Program Cities, all } \\
\text { Households with Children, } \\
\text { SISBEN }<22\end{array}$} & \multicolumn{2}{|c|}{$\begin{array}{c}\text { Panel D: Program Cities, all } \\
\text { Households with Children, } \\
\text { FAU Eligible }\end{array}$} \\
\hline & $\underline{\text { SISBEN Census }}$ & ECV 2010 & SISBEN Census & ECV 2010 & SISBEN Census & ECV 2010 & SISBEN Census & ECV 2010 \\
\hline Total number of people in household & 3.95 & 3.55 & 4.50 & 4.19 & 4.61 & 4.35 & 4.75 & 4.74 \\
\hline Household head completed secondary education & 0.49 & 0.66 & 0.58 & 0.74 & 0.49 & 0.60 & 0.38 & 0.38 \\
\hline Partner of household head completed secondary education & 0.55 & 0.71 & 0.62 & 0.77 & 0.52 & 0.60 & 0.39 & 0.37 \\
\hline Monthly household income (2010 USD) & 310.55 & 1289.57 & 294.77 & 1240.38 & 220.81 & 623.73 & 176.24 & 461.23 \\
\hline House has child & 0.52 & 0.49 & 1.00 & 1.00 & 1.00 & 1.00 & 1.00 & 1.00 \\
\hline Average age of children in house & 10.44 & 10.45 & 10.44 & 10.45 & 10.38 & 10.54 & 10.24 & 10.54 \\
\hline Share of employed people in household & 0.36 & 0.43 & 0.29 & 0.37 & 0.28 & 0.33 & 0.26 & 0.31 \\
\hline Share of formally employed workers in the household & 0.13 & 0.28 & 0.11 & 0.23 & 0.07 & 0.15 & 0.02 & 0.05 \\
\hline Low stratum & 0.76 & 0.57 & 0.80 & 0.65 & 1.00 & 1.00 & 1.00 & 1.00 \\
\hline Mid stratum & 0.24 & 0.37 & 0.20 & 0.31 & 0.00 & 0.00 & 0.00 & 0.00 \\
\hline High stratum & 0.00 & 0.06 & 0.00 & 0.04 & 0.00 & 0.00 & 0.00 & 0.00 \\
\hline SISBEN score & 17.74 & 24.85 & 16.68 & 22.39 & 11.35 & 14.34 & 6.47 & 6.55 \\
\hline \multicolumn{9}{|l|}{$\underline{\text { Dwelling characteristics }}$} \\
\hline Household asset index & 3.87 & 4.75 & 3.78 & 4.65 & 3.36 & 4.19 & 2.45 & 3.39 \\
\hline House has finished floor materials & 0.53 & 0.74 & 0.49 & 0.72 & 0.36 & 0.55 & 0.23 & 0.26 \\
\hline House has indoor water source & 0.78 & 0.95 & 0.77 & 0.94 & 0.70 & 0.91 & 0.50 & 0.76 \\
\hline House has trash collection & 0.97 & 0.98 & 0.97 & 0.98 & 0.96 & 0.96 & 0.92 & 0.85 \\
\hline House has toilet connected to sewage system & 0.93 & 0.95 & 0.92 & 0.94 & 0.90 & 0.88 & 0.82 & 0.68 \\
\hline Number of dormitories per person & 0.57 & 0.66 & 0.44 & 0.57 & 0.39 & 0.50 & 0.34 & 0.43 \\
\hline House has electricity & 1.00 & 1.00 & 1.00 & 1.00 & 1.00 & 1.00 & 0.99 & 1.00 \\
\hline House has gas connection & 0.52 & 0.75 & 0.51 & 0.74 & 0.44 & 0.70 & 0.31 & 0.51 \\
\hline Phone service is shared, conditional on not having a phone & 0.30 & 0.95 & 0.28 & 0.94 & 0.26 & 0.91 & 0.20 & 0.74 \\
\hline Households & $2,447,200$ & 2632 & $1,264,362$ & 1287 & 930,823 & 668 & 431,277 & 161 \\
\hline
\end{tabular}

Notes: Data is from the 2005 census of the poor and the ECV 2010 survey. Panel A includes all households surveyed in the fourteen cities included in the 2007 FAU expansion. Panel B further restricts the sample to households with children of eligible ages (18 years of age and younger). Panel C further limits the sample to households with a SISBEN score of 22 or less. Panel D further limits the sample to households with a SISBEN score under 11, the cutoff for FAU eligibility. All variables - besides household asset index, total number of people in household, monthly household income, and SISBEN score - are dummy variables with the value of 1 if the household has the characteristic, and 0 otherwise. Household asset index is defined as the sum of dummy variables that take the value of 1 if the household's dwelling has: a sewage system, telephone, piped water, toilet, refrigerator, or heater. Incomes from 2005 are converted to 2010 USD by using the consumer price index (CPI) to translate 2005 USD in 2010 terms. Next, the 2010 exchange rate between the USD and COP is used to convert to 2010 USD (See appendix A for details). Incomes from 2010 are converted to 2010 USD using the 2010 exchange rate between the USD and COP. CPI is from the World Bank (http://databank.worldbank.org/). Exchange rate in 2010 is the average USD to COP exchange rate for all days in 2010 taken from the IMF (http://www.imf.org/external/data.htm). Stratum is a measure of socio-economic status. Any household with a stratum value less than 2, either 3 or 4, and either 5 or 6 is defined as low, mid, and high stratum respectively. Houses with finished floor materials are houses with tile, vinyl, tablet, brick, marble, polished wood, finished wood, or carpet as the primary floor material. Share of formally employed workers in the household only includes houses with working members. House has toilet connected to sewage system is conditional on house having a toilet. Not shown are rare characteristics (less than one percent) or those already captured by a comparable measure. 
Table 2. First Stage: FAU Participation as a Function of SISBEN Scores

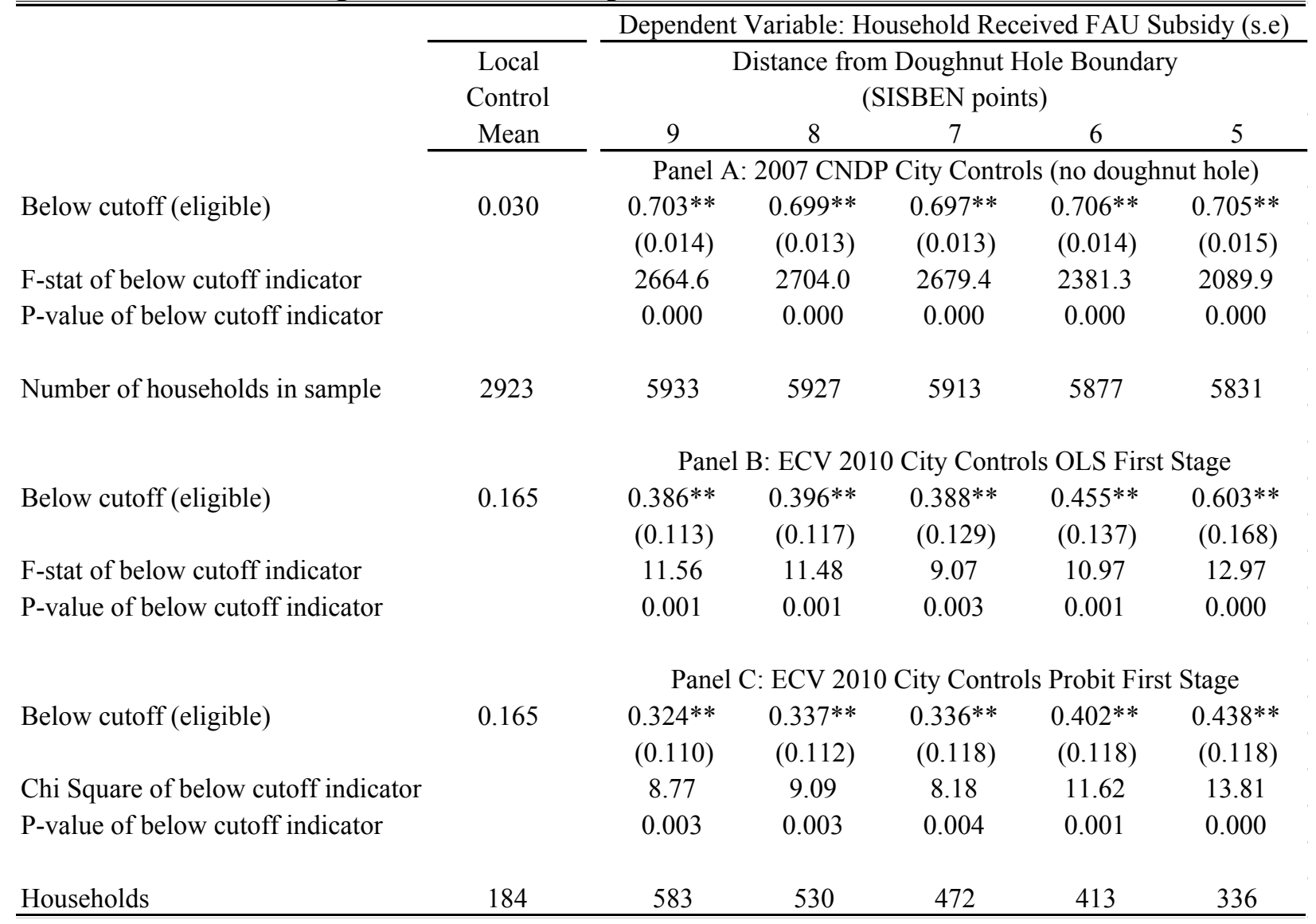

Notes: Data is from the ECV 2010 survey and the 2007 CNDP and is at the household level. Sample restricted to all households in the 2007 FAU expansion cities with at least one child age 18 and younger and a SISBEN score of 22 and lower (the 2007 CNDP data doesn't include Cali and Medellin). In the ECV 2010, doughnut hole is [-1,2] SISBEN points around the FAU eligibility cutoff of 11 SISBEN points. Columns represent bandwidths between 5 and 9 SISBEN units from the doughnut hole boundary (both sides). The regression results presented are the first stage of a 2SLS with the receiving FAU support dummy instrumented with an eligibility dummy that takes the value of 1 if the household's SISBEN score is below the cutoff. The first stage also controls for SISBEN score and an interaction between linear SISBEN score and eligibility. The local control mean is the mean variable value for ineligible households within 5 SISBEN units of the doughnut hold boundary (single side, households above the doughnut hole) or 7 units from the cutoff for the CNDP data. Panel B and C have the same number of households (reported on the bottom row). Robust standard errors are reported in parenthesis. P-values are denoted by: $+\mathrm{p}<0.1$, $* \mathrm{p}<.05, * * \mathrm{p}<.01$. 
Table 3. Fuzzy RD Estimates of Participation on Income, Expenditure, and Formal Employment

\begin{tabular}{|c|c|c|c|c|c|c|}
\hline & & & $\overline{\mathrm{AU} \text { Parti }}$ & pation Es & mate $(\mathrm{s} .6$ & \\
\hline & $\begin{array}{l}\text { Local } \\
\text { Control }\end{array}$ & Dis & nce from & $\begin{array}{l}\text { Joughnut } \\
\text { SBEN poi }\end{array}$ & $\begin{array}{l}\text { Tole Bou } \\
\text { ts) }\end{array}$ & dary \\
\hline Dependent Variable & (s.d.) & 9 & 8 & 7 & 6 & 5 \\
\hline (1) Monthly income (2010 USD) & $\begin{array}{c}606.9 \\
(397.8)\end{array}$ & $\begin{array}{l}388.1 \\
(237.0)\end{array}$ & $\begin{array}{l}316.6 \\
(224.3)\end{array}$ & $\begin{array}{l}643.3+ \\
(312.2)\end{array}$ & $\begin{array}{l}542.4+ \\
(267.8)\end{array}$ & $\begin{array}{l}525.2^{*} \\
(230.3)\end{array}$ \\
\hline (2) Monthly expenditure (2010 USD) & $\begin{array}{c}384.1 \\
(119.5)\end{array}$ & $\begin{array}{l}480.0+ \\
(263.5)\end{array}$ & $\begin{array}{l}385.9 \\
(245.7)\end{array}$ & $\begin{array}{l}566.3+ \\
(317.7)\end{array}$ & $\begin{array}{l}506.2+ \\
(281.3)\end{array}$ & $\begin{array}{l}528.3+ \\
(277.7)\end{array}$ \\
\hline $\begin{array}{l}\text { (3) Household head is formally employed } \\
\text { (binary) }\end{array}$ & 0.32 & $\begin{array}{l}0.43^{*} \\
(0.17)\end{array}$ & $\begin{array}{l}0.45^{*} \\
(0.17)\end{array}$ & $\begin{array}{r}0.51 * * \\
(0.11)\end{array}$ & $\begin{array}{r}0.50 * * \\
(0.12)\end{array}$ & $\begin{array}{r}0.66 * * \\
(0.13)\end{array}$ \\
\hline $\begin{array}{l}\text { (4) Partner of head is formally employed } \\
\text { (binary) }\end{array}$ & 0.32 & $\begin{array}{c}0.26 * * \\
(0.09)\end{array}$ & $\begin{array}{r}0.27^{* *} \\
(0.09)\end{array}$ & $\begin{array}{l}0.15+ \\
(0.07)\end{array}$ & $\begin{array}{l}0.14+ \\
(0.08)\end{array}$ & $\begin{array}{l}0.21+ \\
(0.12)\end{array}$ \\
\hline Households & 184 & 583 & 530 & 472 & 413 & 336 \\
\hline
\end{tabular}

Notes: Data is from the ECV 2010 survey and at the household level. Sample restricted to households in the 2007 FAU expansion cities with a child age 18 and younger and SISBEN scores of 22 or lower. Doughnut hole is [-1,2] SISBEN points around FAU eligibility cutoff of 11 SISBEN points. Columns represent bandwidths between 5 and 9 SISBEN units from the doughnut hole boundary (on both sides). The estimates of FAU receipt effects are from separate regressions in which receipt is instrumented with an indicator for having a SISBEN score below 11 points (eligible). Estimates for monthly income and monthly expenditure are linear IV. Estimates for employment are bivariate probit, with the marginal probability of 1 reported at the cutoff. Other controls not shown include SISBEN score, an interaction of eligible with linear SISBEN score, and city (see equations 1 and 2 for first and second stage). The local control mean is the mean variable value for ineligible households within 5 SISBEN units of the doughnut hold boundary (single side, households above the doughnut hole). Standard deviation of control means are presented in parenthesis under the control means, and robust standard errors are presented in parenthesis under estimates. Number of observations for head formally employed variable are 293, 251, 212, 171, and 131 for bandwidths from 9 to 5 SISBEN units. Number of observations for partner of head formally employed variable are 260, 240, 215, 187, and 145 for bandwidths from 9 to 5 SISBEN units. Currency is converted to 2010 USD (see Appendix A for detail). Total expenditure is the sum of all expenditure categories. Expenditure items are defined in Appendix A. P-values are denoted by: $+\mathrm{p}<0.1, * \mathrm{p}<.05, * * \mathrm{p}<.01$. The critical values are corrected for multiple hypotheses testing using the method described in Benjamini and Hochberg (1995). Each column in the table represents a family of outcomes and the corrected critical value levels for $0.1, .05$, and .01 are $.075, .025$, and .005 for bandwidth $9, .05, .025$, and .005 for bandwidth $8, .1, .025$, and .005 for bandwidth $7, .1, .025$, and .005 for bandwidth 6 , and $.1, .0375$, and .0025 for bandwidth 5 . 
Table 4. Effect of FAU Subsidy on Health and Education Outcomes

\begin{tabular}{|c|c|c|c|c|c|c|c|}
\hline & & & & U Part & pation $\mathrm{E}$ & mate $(\mathrm{s}$ & \\
\hline & & $\begin{array}{l}\text { Local } \\
\text { Control }\end{array}$ & Dis & ce fron & $\begin{array}{l}\text { oughnut } \\
\text { BEN po }\end{array}$ & $\begin{array}{l}\text { ole Bo } \\
\text { s) }\end{array}$ & \\
\hline & Dependent Variable & (s.d.) & 9 & 8 & 7 & 6 & 5 \\
\hline (1) & $\begin{array}{l}\text { Self-reported health--household average } \\
\text { (1-4 scale) }\end{array}$ & $\begin{array}{c}2.91 \\
(0.33)\end{array}$ & $\begin{array}{l}0.74+ \\
(0.30)\end{array}$ & $\begin{array}{l}0.52 \\
(0.24)\end{array}$ & $\begin{array}{c}0.54 \\
(0.29)\end{array}$ & $\begin{array}{l}0.48 \\
(0.26)\end{array}$ & $\begin{array}{l}0.36 \\
(0.20)\end{array}$ \\
\hline (2) & $\begin{array}{l}\text { Paid non-hospital medical consultation last } \\
\text { month -- household average }(0-1 \text { scale })\end{array}$ & $\begin{array}{c}0.07 \\
(0.16)\end{array}$ & $\begin{array}{c}0.17 \\
(0.09)\end{array}$ & $\begin{array}{c}0.17 \\
(0.09)\end{array}$ & $\begin{array}{c}0.18 \\
(0.11)\end{array}$ & $\begin{array}{c}0.11 \\
(0.08)\end{array}$ & $\begin{array}{l}0.09 \\
(0.08)\end{array}$ \\
\hline (3) & $\begin{array}{l}\text { Illness last month that didn't require } \\
\text { hospitalization --household average ( } 0-1 \text { scale) }\end{array}$ & $\begin{array}{c}0.12 \\
(0.19)\end{array}$ & $\begin{array}{l}-0.10 \\
(0.13)\end{array}$ & $\begin{array}{l}-0.12 \\
(0.14)\end{array}$ & $\begin{array}{l}-0.03 \\
(0.14)\end{array}$ & $\begin{array}{c}0.02 \\
(0.13)\end{array}$ & $\begin{array}{l}0.02 \\
(0.11)\end{array}$ \\
\hline (4) & $\begin{array}{l}\text { Fraction of children in household enrolled in } \\
\text { school ( } 0-1 \text { scale) }\end{array}$ & $\begin{array}{c}0.89 \\
(0.29)\end{array}$ & $\begin{array}{l}0.41 \\
(0.26)\end{array}$ & $\begin{array}{l}0.44 \\
(0.27)\end{array}$ & $\begin{array}{c}0.39 \\
(0.33)\end{array}$ & $\begin{array}{c}0.42 \\
(0.32)\end{array}$ & $\begin{array}{l}0.02 \\
(0.24)\end{array}$ \\
\hline & Households & 184 & 583 & 530 & 472 & 413 & 336 \\
\hline
\end{tabular}

Notes: Data is from the ECV 2010 survey and at the household level. Sample restricted to households in the 2007 FAU expansion cities with a child age 18 and younger and SISBEN scores of 22 or lower. Doughnut hole is [-1,2] SISBEN points around FAU eligibility cutoff of 11 SISBEN points. Columns represent bandwidths between 5 and 9 SISBEN units from the doughnut hole boundary (on both sides). The estimates of FAU receipt effects are from separate regressions in which receipt is instrumented with an indicator for having a SISBEN score below 11 points (eligible). All estimates are linear IV. Other controls not shown include SISBEN score, an interaction of eligible with linear SISBEN score, and city (see equations 1 and 2 for first and second stage). The local control mean is the mean variable value for ineligible households within 5 SISBEN units of the doughnut hold boundary (single side, households above the doughnut hole). Standard deviation of control means are presented in parenthesis under the control means, and robust standard errors are presented in parenthesis under estimates. P-values are denoted by: + $\mathrm{p}<0.1, * \mathrm{p}<.05, * * \mathrm{p}<.01$. The critical values are corrected for multiple hypotheses testing using the method described in Benjamini and Hochberg (1995). Each column represents a family, and the corrected critical value levels for $0.1, .05$, and .01 are $.025, .0125$, and .0025 for all bandwidths. 
Table 5. Fuzzy RD Estimates of Participation on Household Head Domain Satisfaction Variables, Life Satisfaction, and Happiness

\begin{tabular}{|c|c|c|c|c|c|c|c|}
\hline & & & & AU Parti & pation $\mathrm{E}$ & imate (s.e & \\
\hline & & $\begin{array}{c}\text { Local } \\
\text { Control }\end{array}$ & Dis & nce from & $\begin{array}{l}\text { oughnu } \\
\text { BEN po }\end{array}$ & $\begin{array}{l}\text { Hole Bou } \\
\text { ts) }\end{array}$ & \\
\hline & Dependent Variable (all binary) & Mean & 9 & 8 & 7 & 6 & 5 \\
\hline (1) & Satisfaction with life & 0.78 & $\begin{array}{c}0.39 \\
(0.52)\end{array}$ & $\begin{array}{c}0.49 \\
(0.36)\end{array}$ & $\begin{array}{c}0.47 \\
(0.27)\end{array}$ & $\begin{array}{r}0.58 * * \\
(0.05)\end{array}$ & $\begin{array}{c}0.14 \\
(0.51)\end{array}$ \\
\hline$(2)$ & Happiness & 0.78 & $\begin{array}{c}0.06 \\
(0.36)\end{array}$ & $\begin{array}{c}0.16 \\
(0.40)\end{array}$ & $\begin{array}{r}0.59 * * \\
(0.05)\end{array}$ & $\begin{array}{c}0.13 \\
(0.31)\end{array}$ & $\begin{array}{l}-0.15 \\
(0.23)\end{array}$ \\
\hline (3) & Satisfaction with income & 0.27 & $\begin{array}{c}0.13 \\
(0.18)\end{array}$ & $\begin{array}{c}0.19 \\
(0.18)\end{array}$ & $\begin{array}{c}0.17 \\
(0.18)\end{array}$ & $\begin{array}{c}0.11 \\
(0.19)\end{array}$ & $\begin{array}{c}0.00 \\
(0.18)\end{array}$ \\
\hline (4) & Satisfaction with work & 0.50 & $\begin{array}{c}0.08 \\
(0.39)\end{array}$ & $\begin{array}{c}0.08 \\
(0.45)\end{array}$ & $\begin{array}{c}0.37 \\
(0.24)\end{array}$ & $\begin{array}{c}0.20 \\
(0.50)\end{array}$ & $\begin{array}{c}0.12 \\
(0.54)\end{array}$ \\
\hline$(5)$ & Satisfaction with food & 0.81 & $\begin{array}{r}0.58^{* *} \\
(0.05)\end{array}$ & $\begin{array}{c}0.57 * * \\
(0.05)\end{array}$ & $\begin{array}{c}0.57 * * \\
(0.06)\end{array}$ & $\begin{array}{c}0.47+ \\
(0.20)\end{array}$ & $\begin{array}{c}0.49 \\
(0.26)\end{array}$ \\
\hline$(6)$ & $\begin{array}{l}\text { Satisfaction with level of control over } \\
\text { one's life }\end{array}$ & 0.89 & $\begin{array}{l}0.03 \\
(0.34)\end{array}$ & $\begin{array}{r}0.25^{* *} \\
(0.06)\end{array}$ & $\begin{array}{r}0.24 * * \\
(0.07)\end{array}$ & $\begin{array}{c}0.01 \\
(0.45)\end{array}$ & $\begin{array}{c}0.01 \\
(0.18)\end{array}$ \\
\hline (7) & Satisfaction with dwelling & 0.71 & $\begin{array}{c}0.18 \\
(0.36)\end{array}$ & $\begin{array}{c}0.31 \\
(0.54)\end{array}$ & $\begin{array}{c}0.57 * * \\
(0.04)\end{array}$ & $\begin{array}{r}0.57 * * \\
(0.04)\end{array}$ & $\begin{array}{c}0.38 \\
(0.20)\end{array}$ \\
\hline$(8)$ & Satisfaction with ability to help others & 0.81 & $\begin{array}{c}0.26 \\
(0.15)\end{array}$ & $\begin{array}{l}0.32+ \\
(0.15)\end{array}$ & $\begin{array}{c}0.22 \\
(0.19)\end{array}$ & $\begin{array}{c}0.19 \\
(0.20)\end{array}$ & $\begin{array}{c}0.13 \\
(0.16)\end{array}$ \\
\hline (9) & Satisfaction with health & 0.78 & $\begin{array}{l}-0.31 \\
(0.24)\end{array}$ & $\begin{array}{l}-0.28 \\
(0.41)\end{array}$ & $\begin{array}{l}-0.28 \\
(0.20)\end{array}$ & $\begin{array}{l}-0.21 \\
(0.36)\end{array}$ & $\begin{array}{l}-0.14 \\
(0.31)\end{array}$ \\
\hline (10) & Satisfaction with education & 0.78 & $\begin{array}{l}-0.22 \\
(0.23)\end{array}$ & $\begin{array}{c}0.10 \\
(0.48)\end{array}$ & $\begin{array}{c}0.17 \\
(0.49)\end{array}$ & $\begin{array}{l}0.29 \\
(0.26)\end{array}$ & $\begin{array}{c}0.31 \\
(0.16)\end{array}$ \\
\hline (11) & Satisfaction with community & 0.78 & $\begin{array}{l}-0.31 \\
(0.13)\end{array}$ & $\begin{array}{l}-0.26 \\
(0.17)\end{array}$ & $\begin{array}{l}-0.18 \\
(0.22)\end{array}$ & $\begin{array}{l}-0.20 \\
(0.25)\end{array}$ & $\begin{array}{l}-0.07 \\
(0.38)\end{array}$ \\
\hline (12) & Satisfaction with level of security & 0.53 & $\begin{array}{l}-0.39 \\
(0.23)\end{array}$ & $\begin{array}{l}-0.30 \\
(0.31)\end{array}$ & $\begin{array}{c}0.09 \\
(0.57)\end{array}$ & $\begin{array}{l}0.28 \\
(0.41)\end{array}$ & $\begin{array}{c}0.14 \\
(0.38)\end{array}$ \\
\hline (13) & Satisfaction with friends & 0.83 & $\begin{array}{l}-0.09 \\
(0.35)\end{array}$ & $\begin{array}{c}0.24 \\
(0.47)\end{array}$ & $\begin{array}{c}0.36 \\
(0.26)\end{array}$ & $\begin{array}{l}0.47^{*} \\
(0.16)\end{array}$ & $\begin{array}{c}0.23 \\
(0.21)\end{array}$ \\
\hline
\end{tabular}


(14) Average Treatment Effect: Domain satisfaction variables (11 items)

(15) Average Treatment Effect: satisfaction with life and happiness ( 2 items)

Households
0.72

0.78

$$
\begin{gathered}
0.17 \\
(0.30)
\end{gathered}
$$

$0.59 * *$

$(0.05)$

$0.57 * *$

$(0.05)$
0.17

$-0.10$

184

530

472

413

336

Notes: Data is from the ECV 2010 survey and at the household level. Sample restricted to households in the 2007 FAU expansion cities with a child age 18 and younger and SISBEN scores of 22 or lower. Doughnut hole is [-1,2] SISBEN points around FAU eligibility cutoff of 11 SISBEN points. Columns represent bandwidths between 5 and 9 SISBEN units from the doughnut hole boundary (on both sides). The estimates of FAU receipt effects are from separate regressions in which receipt is instrumented with an indicator for having a SISBEN score below 11 points (eligible). Estimates are bivariate probit, with the marginal probability of 1 reported at the cutoff. Other controls not shown include SISBEN score, an interaction of eligible with linear SISBEN score, and city (see equations 1 and 2 for first and second stage). The local control mean is the mean variable value for ineligible households within 5 SISBEN units of the doughnut hold boundary (single side, households above the doughnut hole). Satisfaction with level of dignity and satisfaction with family are not reported because there is very little variation when converted to a binary variable. Robust standard errors are presented in parenthesis under estimates. Average treatment effects are variance-weighted averages and standard errors as described in Cooper et al. (2009). P-values are denoted by: + $\mathrm{p}<0.1, * \mathrm{p}<.05, * * \mathrm{p}<.01$. The critical values are corrected for multiple hypotheses testing using the method described in Benjamini and Hochberg (1995). Each column represents a family, and the corrected critical value levels for $0.1, .05$, and .01 are $.015, .004$, and .0007 for bandwidth $9, .031, .015$, and .003 for bandwidth $8, .031$, .015 , and .003 for bandwidth $7, .023, .011$, and .001 for bandwidth 6 , and $.008, .004$, and .0007 for bandwidth 5 . 
Figure 1. Baseline and 2010 FAU Participation Discontinuity Around Eligibility Cutoff

Panel A. 2007 CNPD Baseline Data

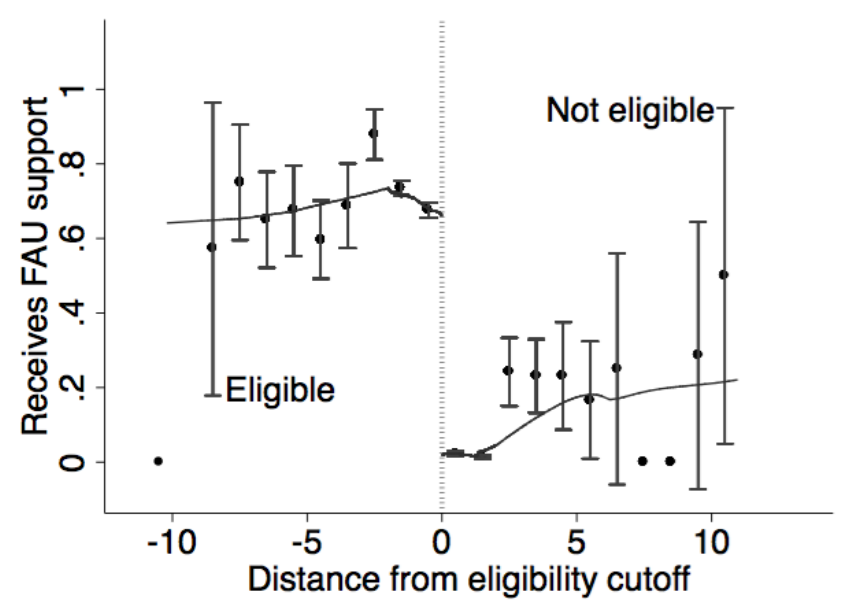

Panel B. ECV 2010 Data, Doughnut Hole Between -1 and 2

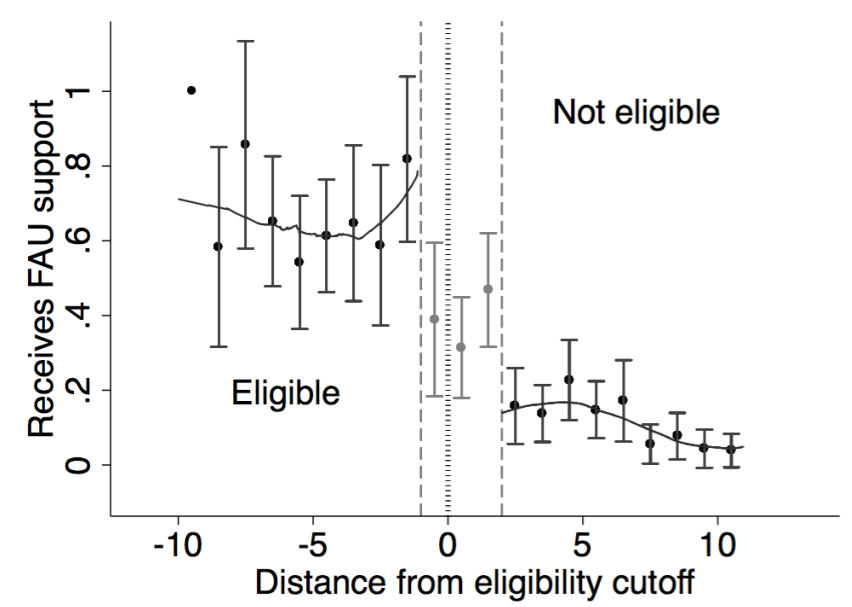

Notes: Error bars represent $90 \%$ confidence intervals around average FAU subsidy receipt in bin with one unit width. If no confidence interval is reported, there is no variance within bin. SISBEN scores are normalized to be zero at the 11-point eligibility cutoff (shown by the vertical line at zero). Data for panel A is from the baseline CNPD survey, which oversampled households near the 11-point eligibility cutoff. Data from Panel B is from the ECV 2010 survey and SISBEN scores are estimated as explained in the text. Data from both figures are limited to households from cities included in the 2007 FAU expansion with children age 18 and younger and a SISBEN score under 22. The 2007 CNPD baseline data excludes Cali and Medellin program cities. The ECV 2010 data includes all fourteen FAU program cities. Dashed vertical lines in panel B represent the doughnut hole boundary. In all panels, lowess curves are fit to FAU program participation over SISBEN score. In panel A lowess curves are fit separately on either side of the eligibility cutoff and in panel B lowess curves are fit separately on either side of the $[-1,2]$ doughnut hole. 
Figure 2. Density of Households over SISBEN Scores, 2005 SISBEN Census and ECV 2010 Data

Panel A: 2005 SISBEN Census

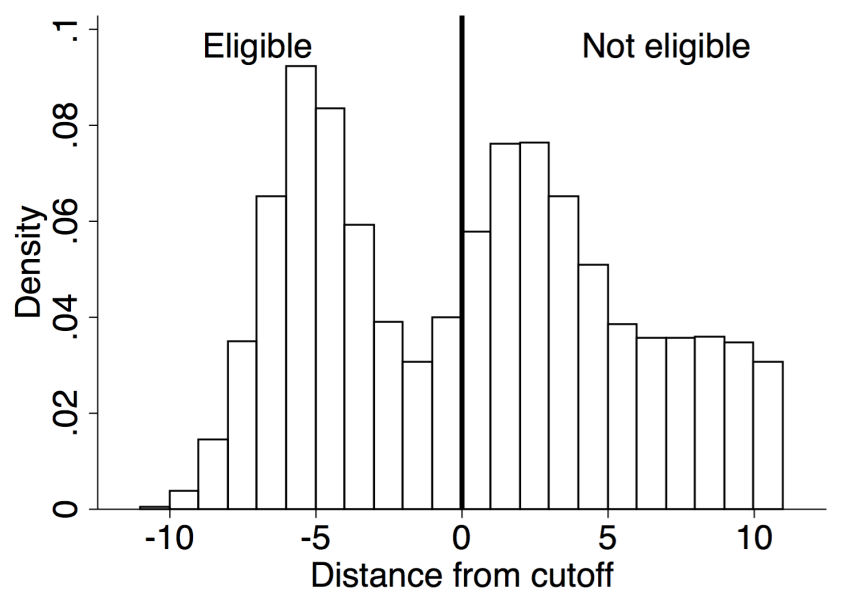

Panel B: ECV 2010

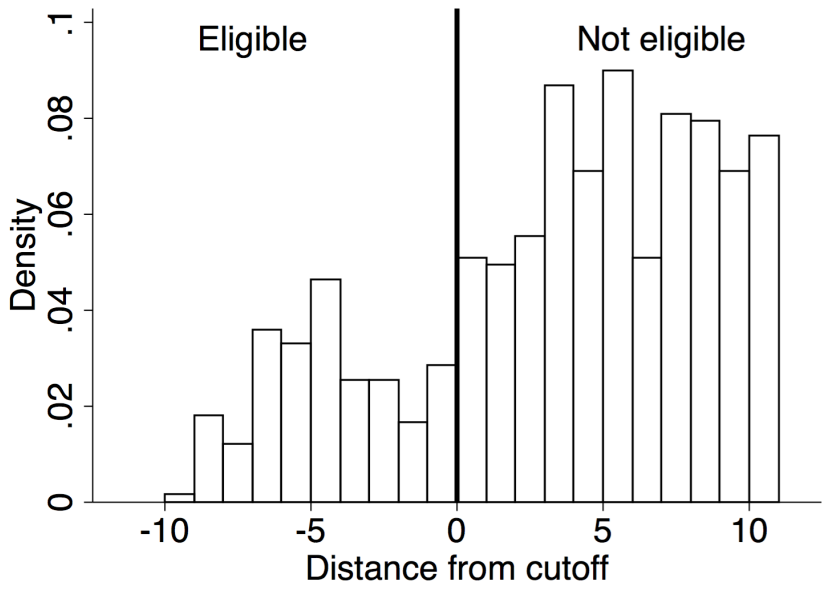

Notes: Data for the Panel A is from the 2005 SISBEN census. Data for the Panel is from the ECV 2010 survey. Data in both panels are limited to households from all 14 cities included in the 2007 FAU expansion with children 18 years of age and younger and a SISBEN score under 22. SISBEN scores are shifted to represent the distance from the eligibility cutoff (zero at the 11-point eligibility cutoff; shown by the vertical line at zero). 


\section{Figure 3. Income, Expenditure, and Formal Employment Outcomes Over SISBEN Scores}

a: Household Income

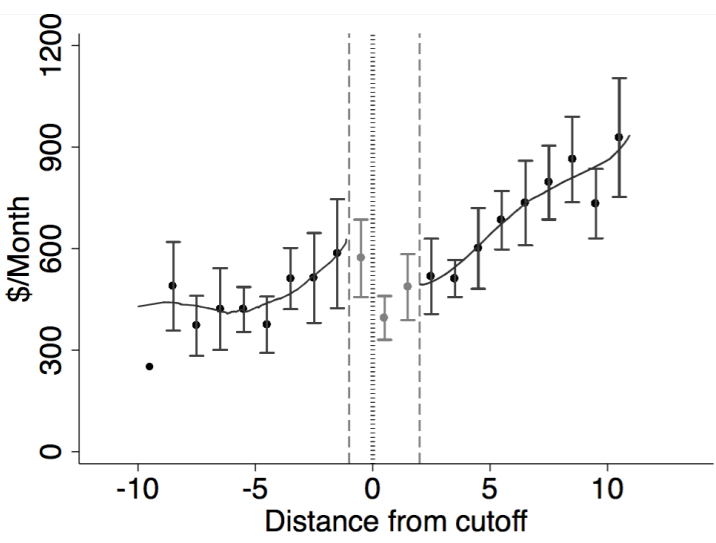

d. Partner of Head Formally

Employed

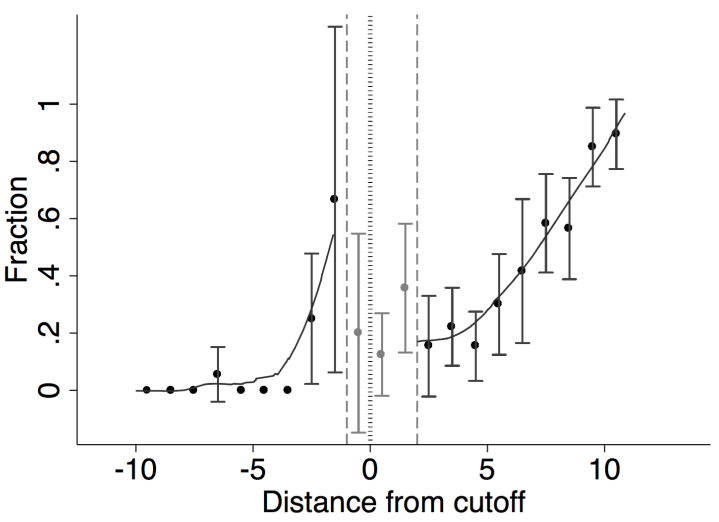

b: Total Expenditure

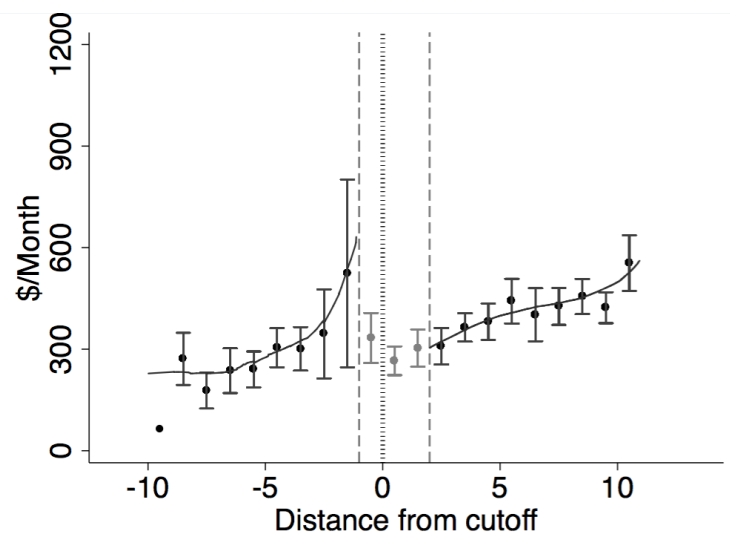

c. Household Head Formally

Employed

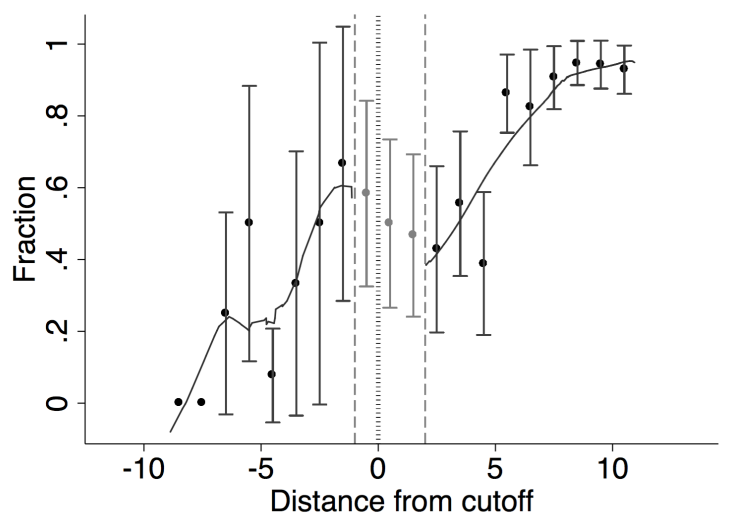

Notes: Data is from the ECV 2010 survey and at the household level. SISBEN scores are estimated as explained in the text and normalized to be zero at the eligibility cutoff. Dashed vertical lines represent the doughnut hole boundary. Lowess curves are fit separately on either side of the doughnut hole. Error bars represent $90 \%$ confidence intervals around average variable values in bins with one unit width. If no confidence interval is reported, there is no variance within the bin. Data includes households from all fourteen cities included in the 2007 FAU expansion with children age 18 or younger and a SISBEN score under 22. Currency is converted to 2010 USD (see Appendix A for detail). Variables are defined in Appendix A. Total expenditure is the sum of all expenditure categories. 


\section{Figure 4. Health and Education Outcomes Over SISBEN Scores}

a: Self-reported health - Household Average

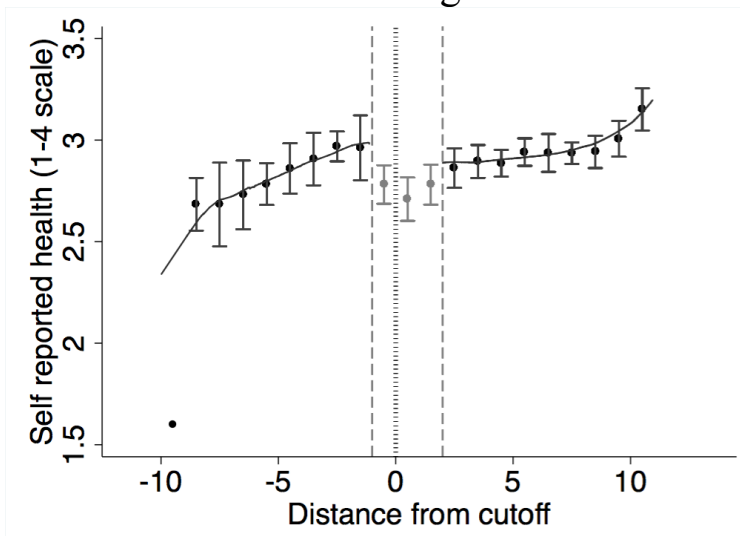

d. Child Enrollment - Household Average

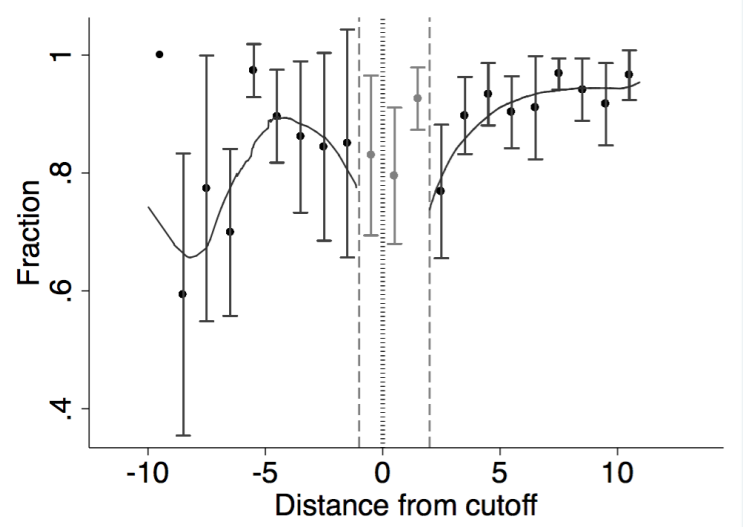

b: Paid Non-hospital Medical Consultation Last Month -- Household Average

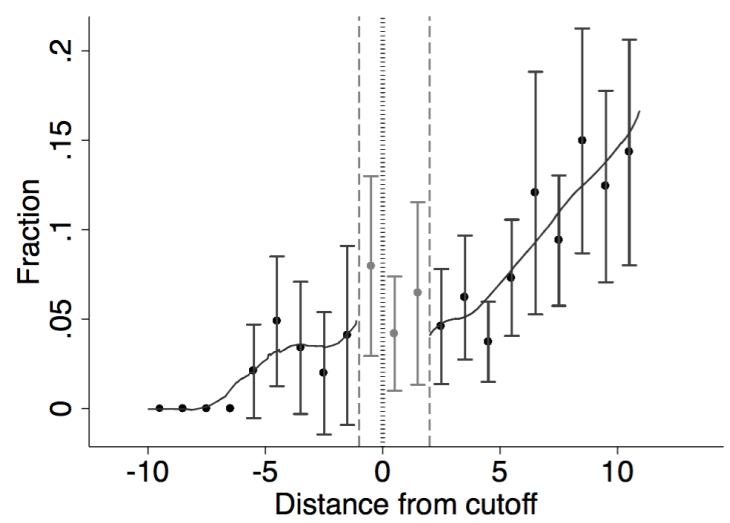

c: Illness Last Month that didn't Require Hospitalization -- Household Average

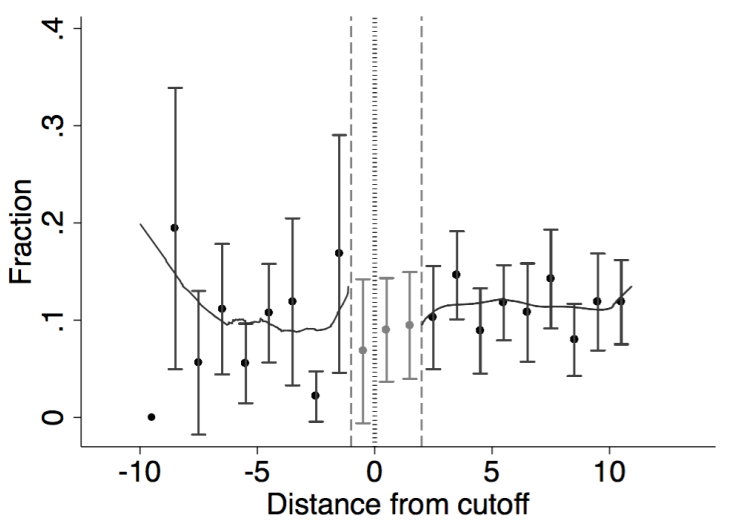

Notes: Data is from the ECV 2010 survey and at the household level. SISBEN scores are estimated as explained in the text and expressed in terms of the distance from the eligibility cutoff. Dashed vertical lines represent the doughnut hole boundary. Lowess curves are fit separately on either side of the doughnut hole. Red lines represent $90 \%$ confidence intervals around average variable values in bins with one unit width. If no confidence interval is reported, there is no variance within bin. Data includes households from all fourteen cities included in the 2007 FAU expansion with children age 18 or younger and a SISBEN score under 22 . 
Figure 5. Household Head Domain Satisfaction Variables, Life Satisfaction, and Happiness over SISBEN scores

a: Satisfaction with Life

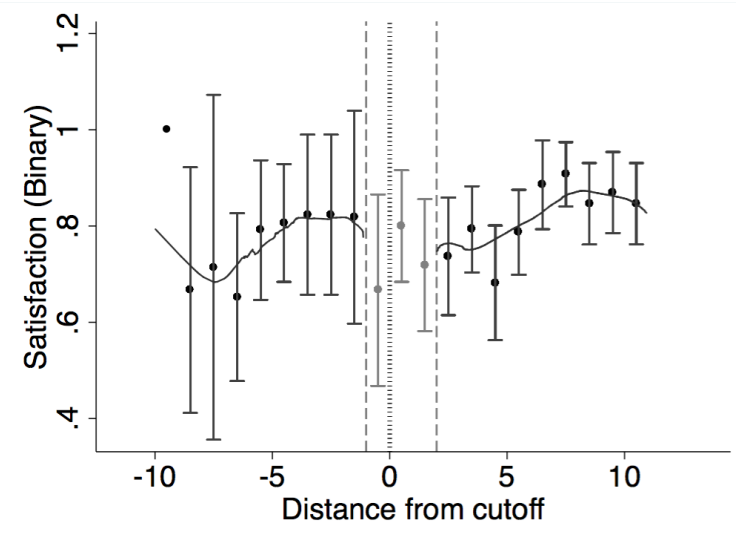

d: Work

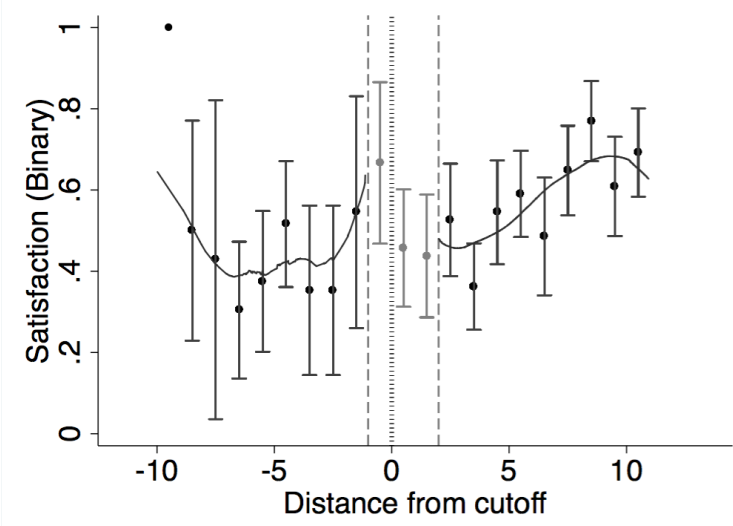

b: Happiness

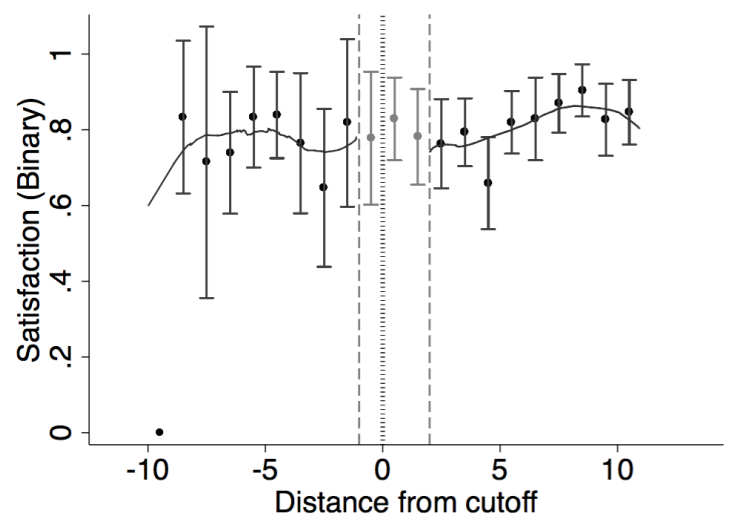

e: Food

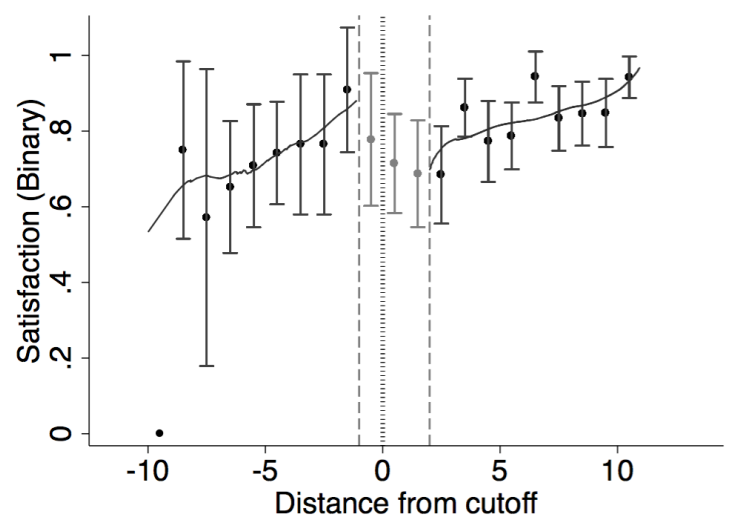

c: Income

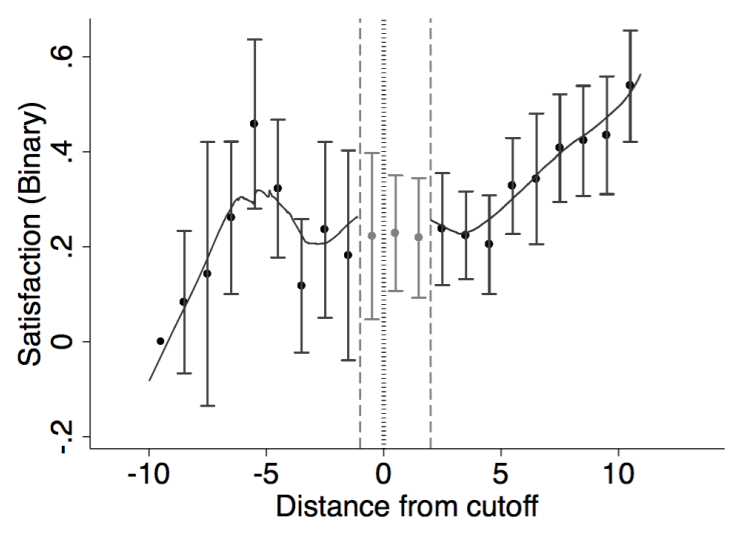

f: Level of Control over One's Life

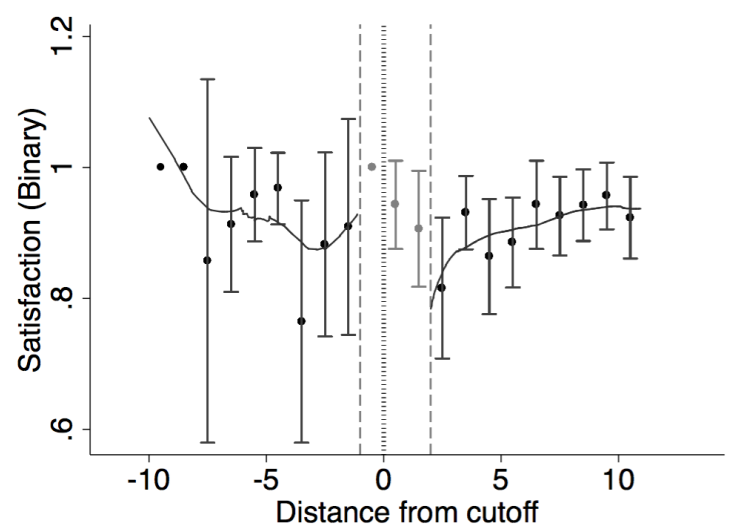


g: Dwelling

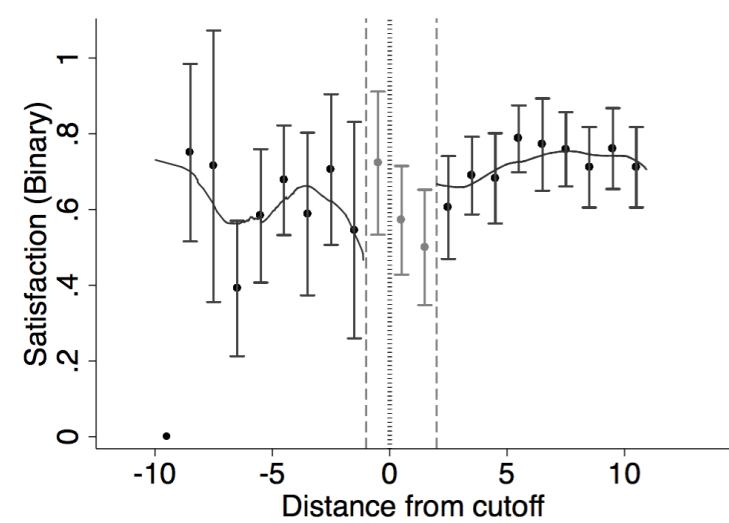

$\mathrm{j}$ : Education

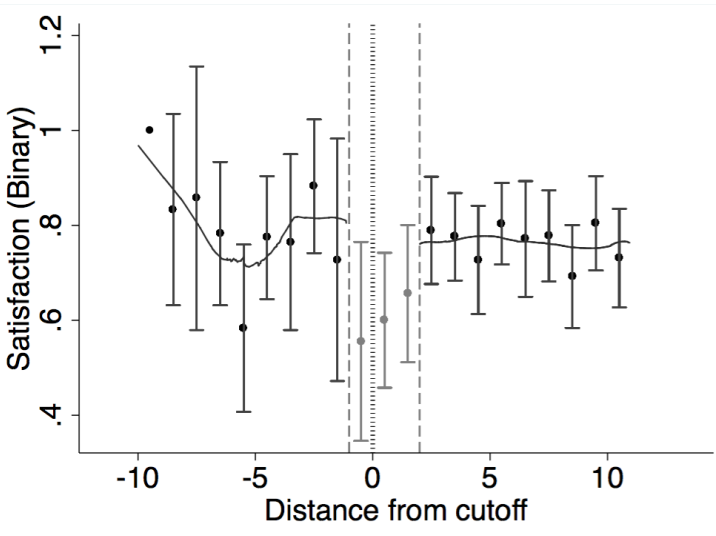

h: Ability to Help Others

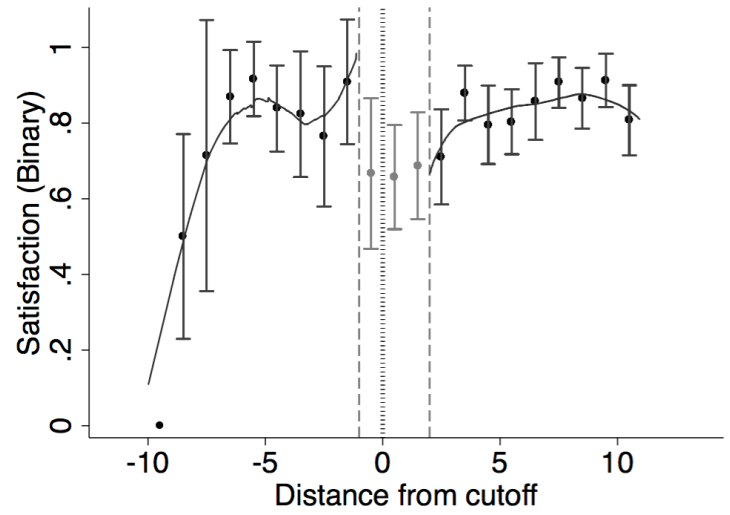

k: Community

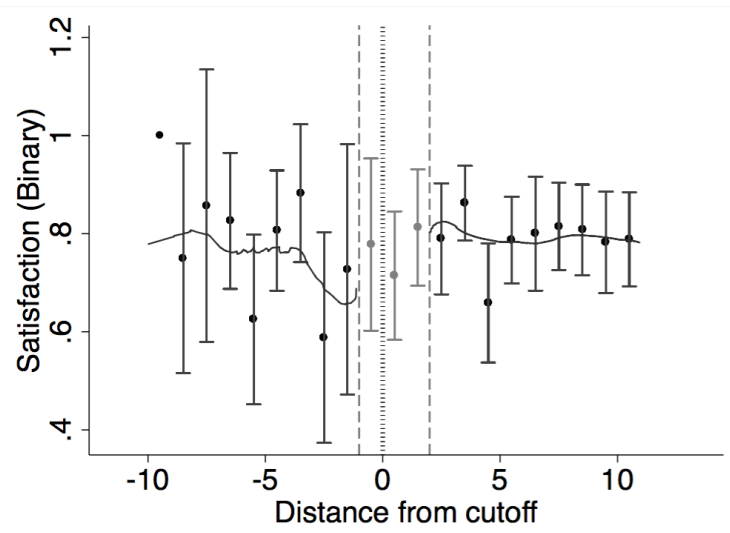

i: Health

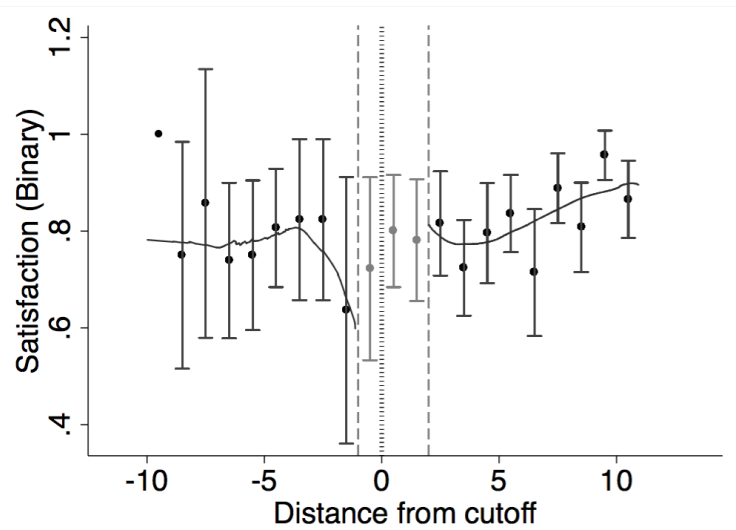

1: Level of Security

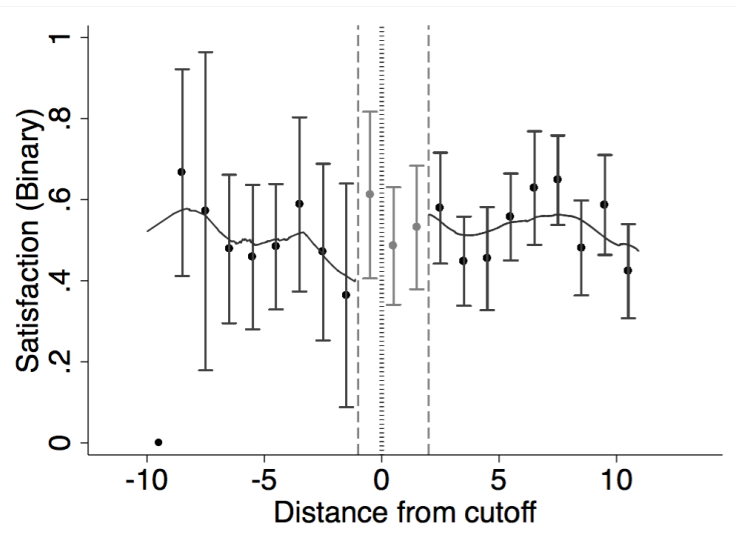


m: Friends

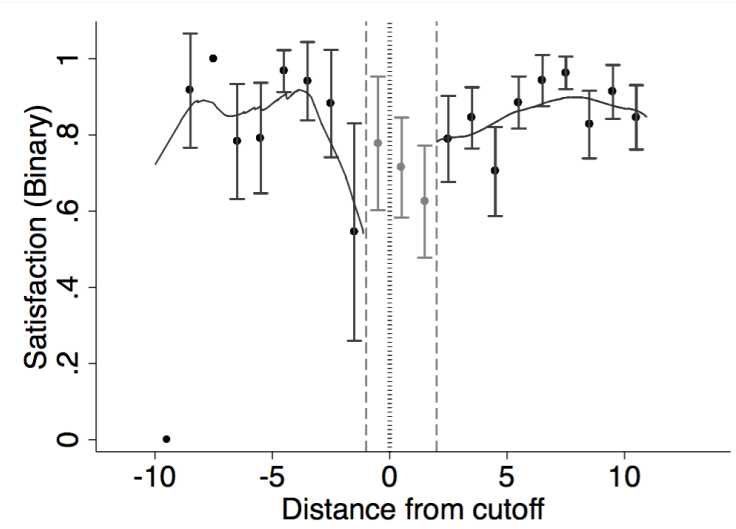

n: Average Treatment Effect: Domain Satisfaction Variables

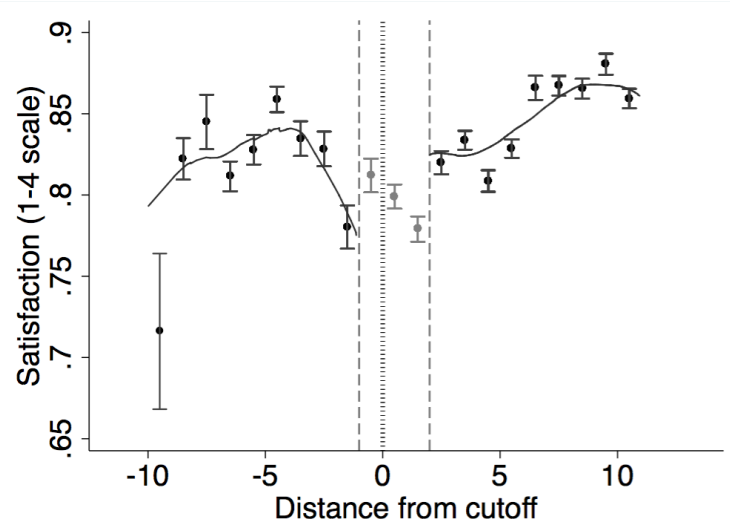

o: Average Treatment Effect: Evaluative Variables

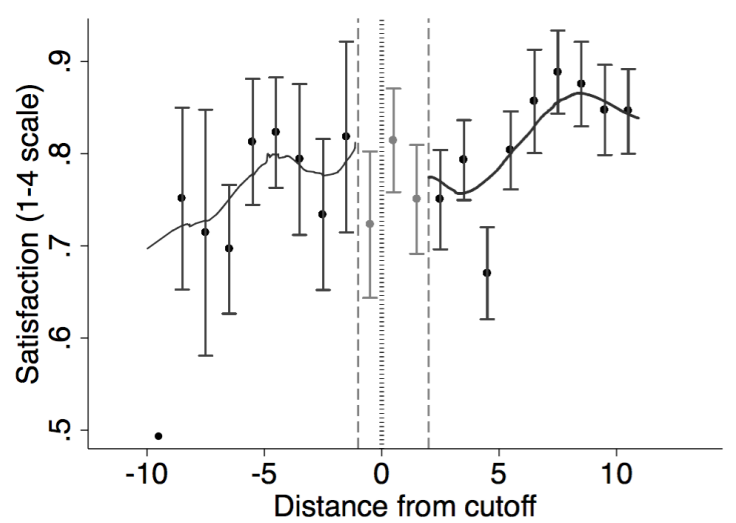

Notes: Data is from the ECV 2010 survey and at the household level. SISBEN scores are estimated as explained in the text and expressed in terms of the distance from the eligibility cutoff. Satisfaction variables are converted from a 1-4 scale to binary, with responses 1 and 2 recoded as 0 , and responses 3 and 4 recoded to 1. Dashed vertical lines represent the doughnut hole boundary. Lowess curves are fit separately on either side of the doughnut hole. Error bars represent $90 \%$ confidence intervals around average variable values in bins with one unit width. If no confidence interval is reported, there is no variance within bin. Data includes households from all cities included in the fourteen 2007 FAU expansion with children age 18 or younger and a SISBEN score under 22. 


\section{Appendix A. Definition of variables from EVC 2010}

Amounts in Colombian pesos (COP) are converted to 2010 USD using the average exchange rates between the COP and USD from Jan 1 to Dec 312010

Exchange rates are taken from the International Monetary Fund:

https://www.imf.org/external/np/fin/ert/GUI/Pages/CountryDataBase.aspx

Exchange rate used $=1897.98$ COP per USD

\section{Household Characteristics}

Total Number of People in Household - Response to the question, "How many people make up this household?"

Monthly Household Income - Total monthly household income as reported by the survey respondent and converted to 2010 USD.

House has finished floor materials - Response to the question, "What is the predominant material of the floors?" Finished floor materials are defined as tile, vinyl, tablet, brick, marble, polished wood, finished wood, or carpet

House has indoor water source - Dummy variable taking the value of 1 if the household dwelling's water supply is located within the house.

House has trash collection - Dummy variable taking the value of 1 if the household's dwelling has trash collection.

House has toilet connected to sewage system - Dummy variable taking the value of 1 if the household has a toilet that is connected to the public sewage system.

Number of dormitories per person - Calculated as the number of rooms where people sleep divided by the total number of people in household.

House has electricity - Dummy variable taking the value of 1 if the household's dwelling has electricity.

House has gas connection - Dummy variable taking the value of 1 if the household's dwelling has a connection to the public gas network.

House has shower - Dummy variable taking the value of 1 if the household's dwelling has a bathroom with a shower.

House has child - Dummy variable taking the value of 1 if the household reports at least one member of the household is 18 year old or younger. 
Number of Toilets - Number of toilets in household's dwelling.

Phone service is shared - Dummy variable taking the value of 1 if household shares a phone service. This variable is only calculated for households that do not have a private phone.

Stove connected to public gas network - Dummy variable taking the value of 1 if the material used as fuel for cooking is gas, and the gas comes from the public gas network.

House has washing machine - Dummy variable taking the value of 1 is the household's dwelling has a washing machine for clothes.

House has air conditioning - Dummy variable taking the value of 1 is the household's dwelling has air conditioning.

House has cable T.V. - Dummy variable taking the value of 1 is the household's dwelling has cable T.V.

House has hot water - Dummy variable taking the value of 1 is the household's dwelling has a gas or electric water heater.

Low stratum - Dummy variable taking the value of 1 if the household belongs to stratum of 2 or lower. Stratum is a proxy for socio-economic status defined by neighborhood. The range of stratum values ranges between 0 and 6 .

Mid stratum - Dummy variable taking the value of 1 if the household belongs to stratum of 3 or 4. Stratum is a proxy for socio-economic status defined by neighborhood. The range of stratum values ranges between 0 and 6 .

High stratum - Dummy variable taking the value of 1 if the household belongs to stratum of 5 or 6. Stratum is a proxy for socio-economic status defined by neighborhood. The range of stratum values ranges between 0 and 6 .

Discretionary items are defined as: tobacco items, matches or lighters; bus, taxi, or metro tickets; alcoholic beverages, home vehicle, parking fees, shoe polishes, newspapers and magazines, gambling, eating outside of the house, domestic services, gifts to other households.

Household expenditure on services and personal items in past month (2010 USD) - The total expenditure on the following items in the past 30 days: mail, fax, toothpaste, soap, shampoo, toilet paper, deodorant, towels, detergent, disinfectant, combs, napkins cotton, gas, disinfectants, alcohol, Band-Aids, contraceptives, aspirin and other pharmaceutical drugs, socks/pantyhose for women, light bulbs, batteries, other electronics, washed and ironed clothes services, haircuts, manicures, entertainment, maid service, internet, credit card payments, cable T.V., monetary transfers to other homes (helping father, brother, children, etc.), or medicines consumed regularly. The total expenditure is converted to 2010 USD. 
Household expenditure on discretionary items in past month (2010 USD) - The total expenditure on the following items in the past 7 days (multiplied by 4 to convert to monthly expenditure): tobacco items, matches or lighters; bus, taxi, or metro tickets; alcoholic beverages, home vehicle, parking fees, shoe polishes, newspapers and magazines, gambling, eating outside of the house, domestic services, gifts to other households. The total expenditure is converted to 2010 USD.

Household expenditure on food in past month (2010 USD) - The total expenditure on the following items in the past 7 days (multiplied by 4 to convert to monthly expenditure): baked items, dairy items, eggs, beef, pork, lamb, chicken, fish, frozen fish, cured meats, vegetables, fruits, unprocessed grains, oils and butter, seasonings and condiments, canned foods, sweets, juices, water, or other food. The total expenditure is converted to 2010 USD.

Household expenditure on durable goods in past month (2010 USD) - The total expenditure on the following items in the past year (divided by 12 to convert to monthly expenditure): furniture, house repairs (plumbing, paint, electricity), pillows, blankets, and bed related products, eating utensils, T.V., vacuum cleaners, hotels, air travel, vehicles, motorcycles, real estate, extraordinary fees (vehicular taxes, rental taxes and other taxes, complementary insurance for fire, theft, vehicles, rings, watches, jewelry, etc.) art, livestock, pets, personal computers, computer accessories, cellular phones, or gaming consoles, such as, playstation, xbox, nintendo, Gameboy. The total expenditure is converted to 2010 USD,

Household semi-durable goods expenditure in past months (2010 USD) - The total expenditure on the following items in the past three months (divided by 3 to convert to monthly expenditure): clothes, shoes, clothing repairs, fabrics for clothing, vehicle repairs, books, discs, cd's, repairs of semi-durable goods, inter-municipal transport or ferries, games, movies, or DVDs. The total expenditure is converted to 2010 USD.

Asset Index - The sum of dummy variables that take the value of 1 if the household's dwelling has: a sewage system, telephone, piped water, toilet, refrigerator, or heater. The possible range of values for the asset index is 0 to 6 .

SISBEN score - To create SISBEN scores, we use the Colombian government's (undisclosed) weighting scheme that takes into account households' socio-economic characteristics including material living standard of the dwelling (floor and roof materials, number of rooms, stove type, access to piped water, sewage, electricity and trash collection), strata (a proxy measure of socioeconomic status based on neighborhood), household size, education of the household head and his/her partner and formal employment of the head and his/her partner.

\section{Household Member Characteristics}

Average age of children in the house - The average age of all members of the household who are 18 years old and younger. 
Household head completed secondary education - Dummy variable that takes the value of 1 if the household head has completed a secondary level of education.

Partner of household head completed secondary education- Dummy variable that takes the value of 1 if the partner of the household head has completed a secondary level of education.

Share of employed people in household - The number of people reporting that working is their primary activity over the past week divided by the total number of people in the household.

Share of formally employed workers in the household - A person is considered formally working if they are contributing to social security and they spend the majority of their time working. The number of people formally working is divided by the total number of people in the household to get the share of formally employed workers.

Head of household is formally working - A dummy taking the value of 1 if the head of the household is formally working. A person is considered formally working if they are contributing to social security and they spend the majority of their time working.

Partner of household head is formally working - A dummy taking the value of 1 if the partner of the household head is formally working. A person is considered formally working if they are contributing to social security and they spend the majority of their time working.

Paid non-hospital medical consultation last month - A dummy variable that takes the value of 1 if the household paid to see a doctor for medical treatment that does not include hospitalization in the past month.

Self-reported health - The self-reported health of the household head on a scale of 1 to 4 , coded (translated to English): 1 (poor), 2 (fair), 3 (good), 4 (very good).

Hospitalized last year - Dummy value that takes the value of 1 if hospitalized in past year.

Illness last month that didn't require hospitalization - Dummy value that takes the value of 1 if had an illness that did not require hospitalization within the past month.

Fraction of children in household enrolled in school - The fraction of children in a household age 18 and under that are currently enrolled in school.

Fraction of literate children in household- The fraction of children in a household age 18 and under that are literate.

\section{Subjective Satisfaction Variables}

The following subjective satisfaction variables are asked as prompts following the general question (translated to English), "How satisfied or dissatisfied are you with the following aspects?" The response options range from 1 to 4 and are coded: 1 (very dissatisfied), 2 (dissatisfied), 3 (satisfied), 4 (very satisfied). The question is only asked to the household head. 
Household head satisfaction with life - Response to the prompt, "life in general"

Household head satisfaction with dignity - Response to the prompt "dignity"

Household head satisfaction with ability to help others - Response to the prompt "ability to help others"

Household head satisfaction with food - Response to the prompt "food"

Household head satisfaction with dwelling - Response to the prompt "dwelling"

Household head satisfaction with income - Response to the prompt "income"

Household head satisfaction with work - Response to the prompt "work"

Household head satisfaction with family - Response to the prompt "family"

Household head satisfaction with friends - Response to the prompt "friends"

Household head satisfaction with level of security - Response to the prompt "level of security"

Household head satisfaction with health - Response to the prompt "health"

Household head satisfaction with community - Response to the prompt "community"

Household head satisfaction with control over one's life - Response to the prompt "control over one's life"

Household head satisfaction with education - Response to the prompt "education" 


\section{Appendix B}

Figure B-1: Continuity of Variables around the Eligibility Cutoff

a: Total Number of People in Household

2005 SISBEN Census

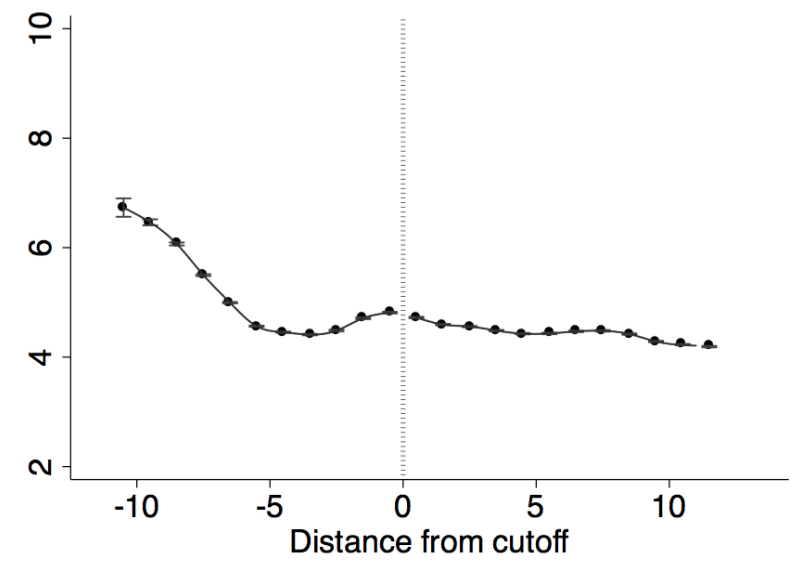

ECV 2010

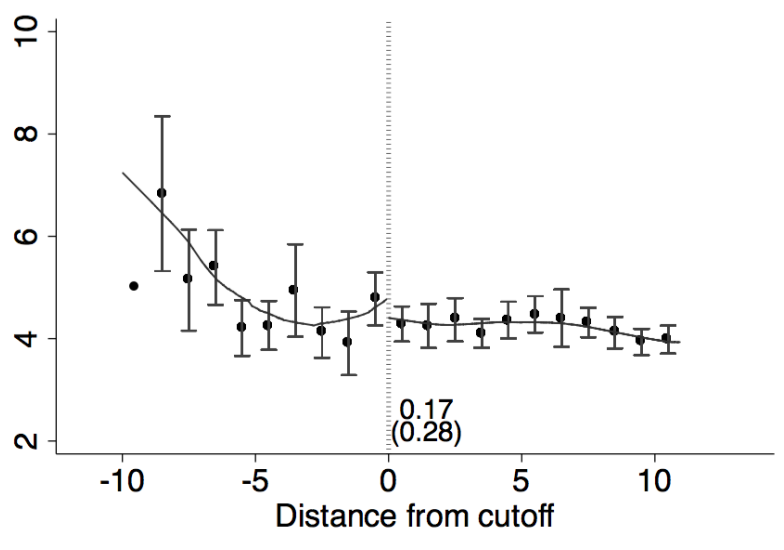

b: Household Head Completed Secondary Education

2005 SISBEN Census

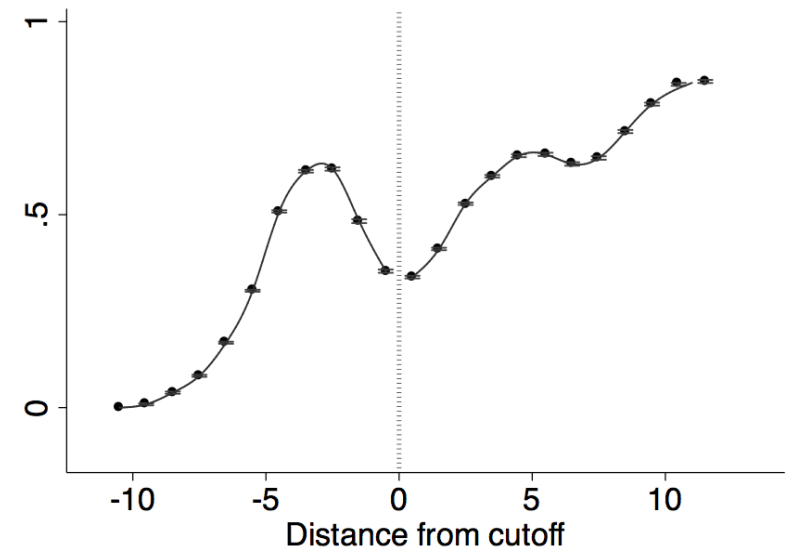

ECV 2010

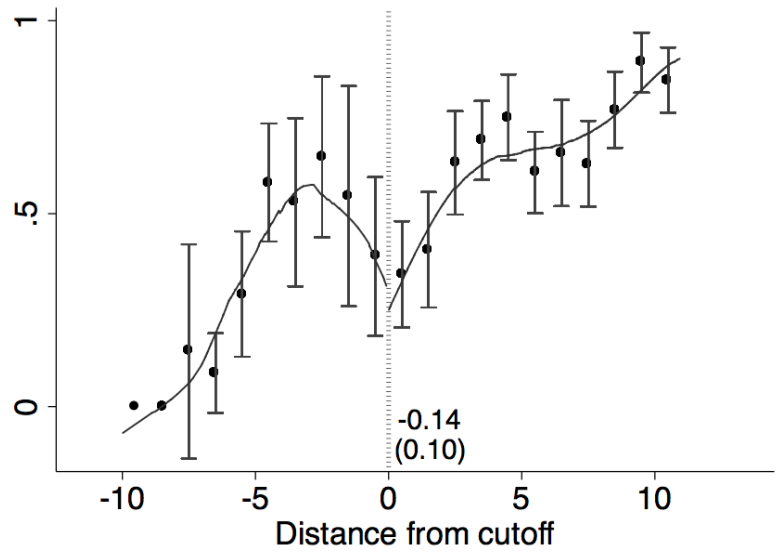

c: Partner of Household Head Completed Secondary Education 2005 SISBEN Census

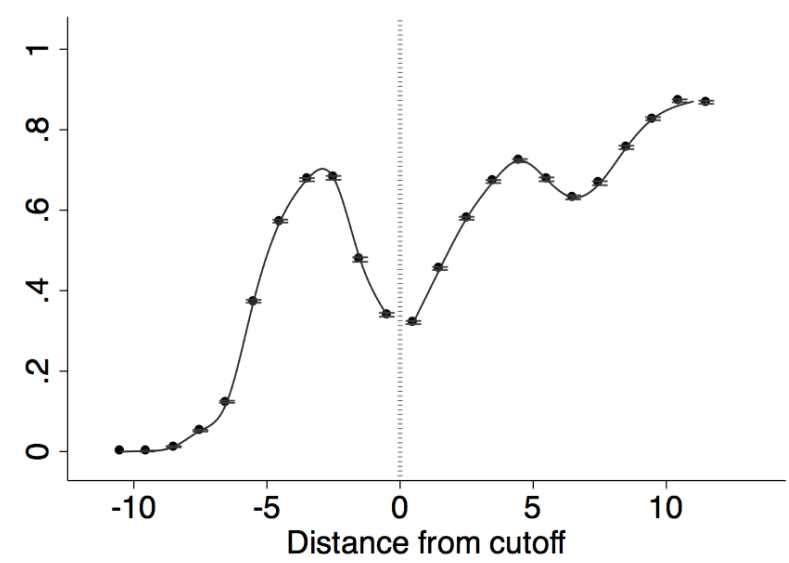

ECV 2010

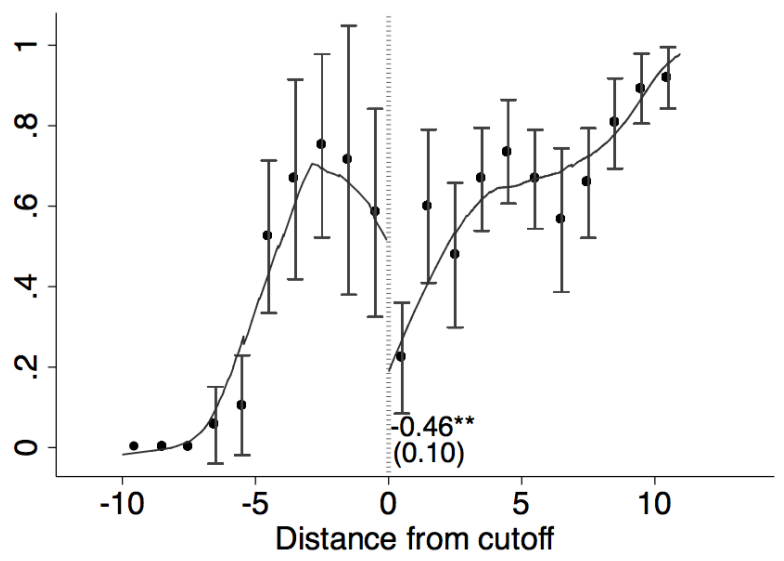


d: Average Age of Children in House 2005 SISBEN Census

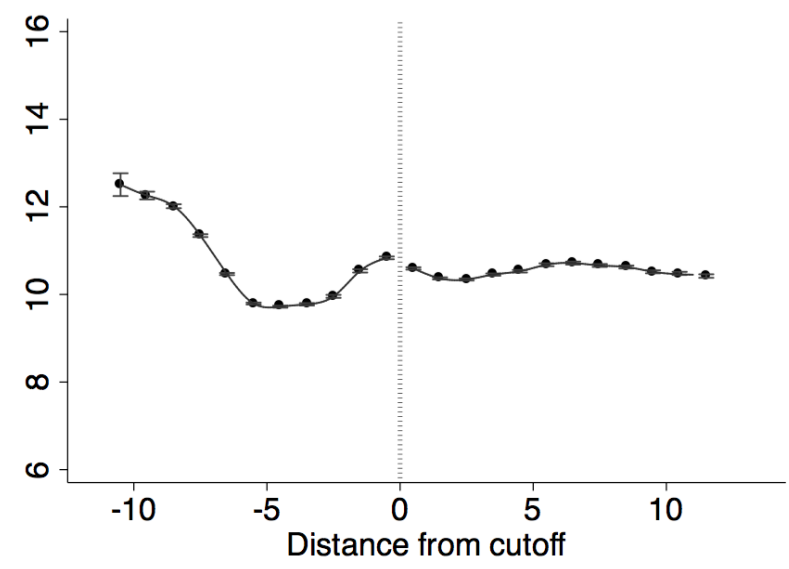

e: House has Finished Floor Materials 2005 SISBEN Census

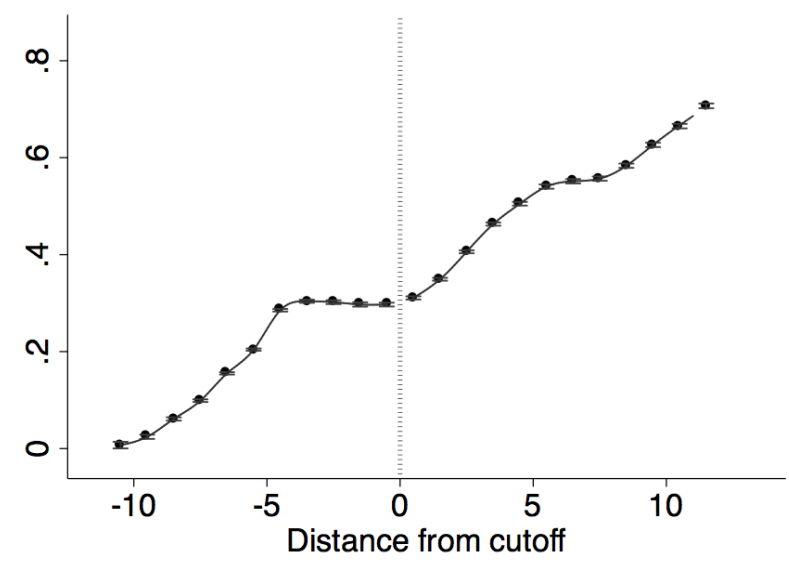

f: House has Indoor Water Source 2005 SISBEN Census

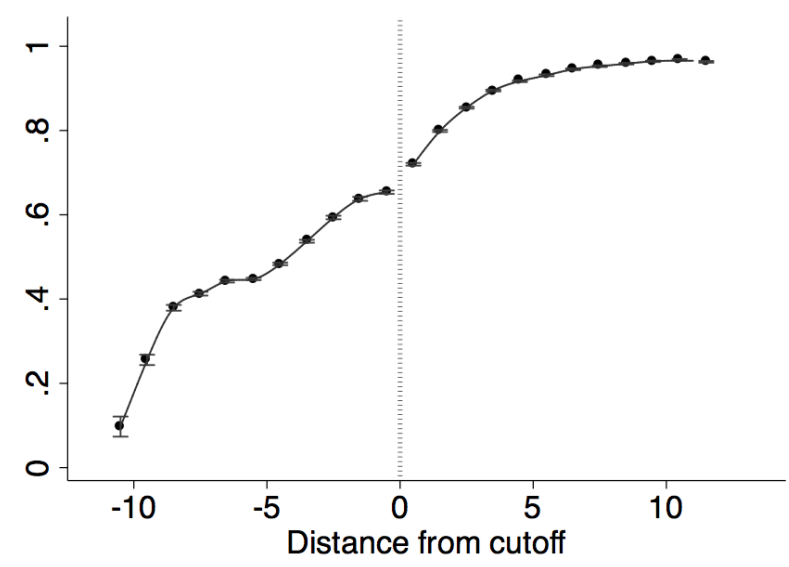

ECV 2010

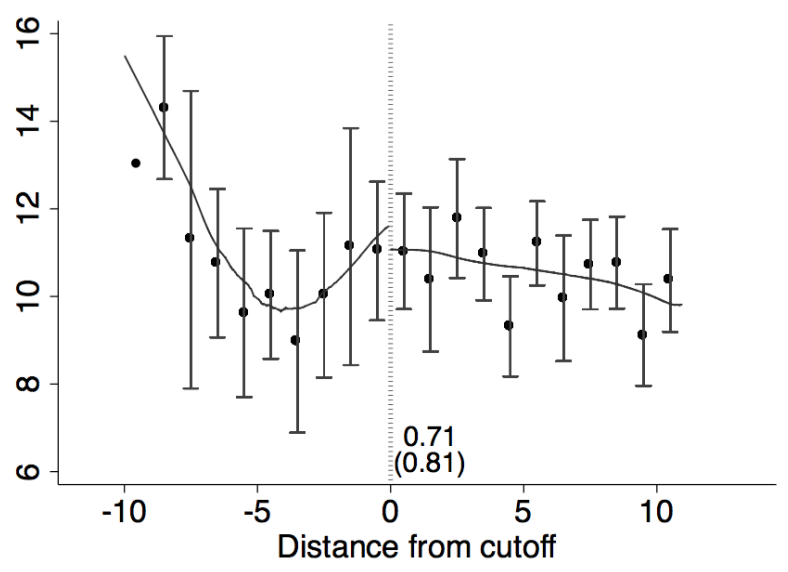

ECV 2010

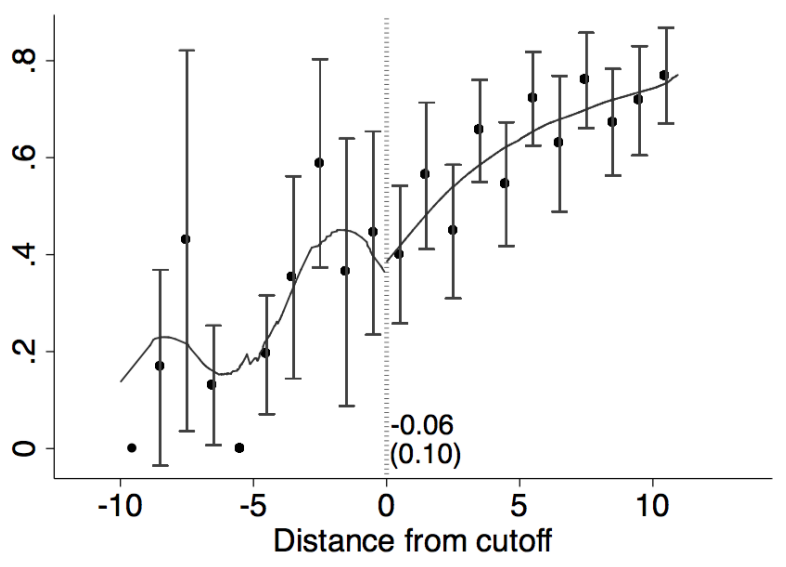

ECV 2010

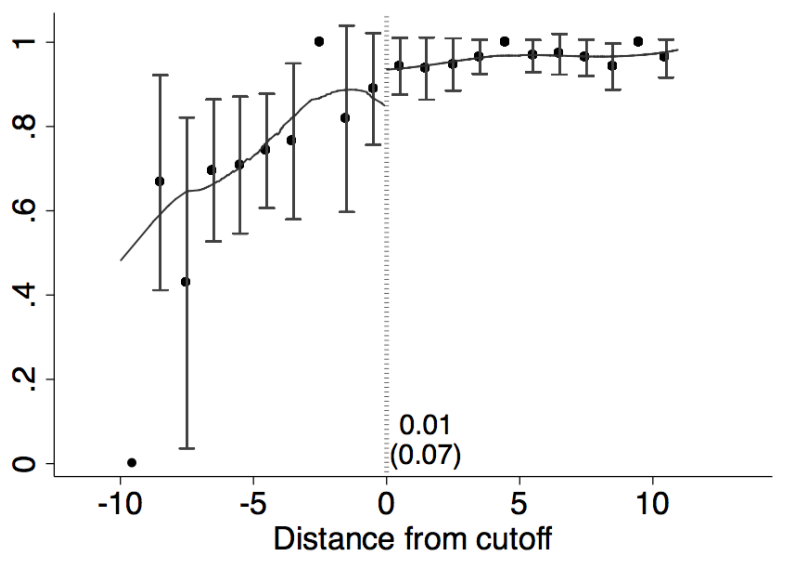


g: House has Trash Collection

2005 SISBEN Census

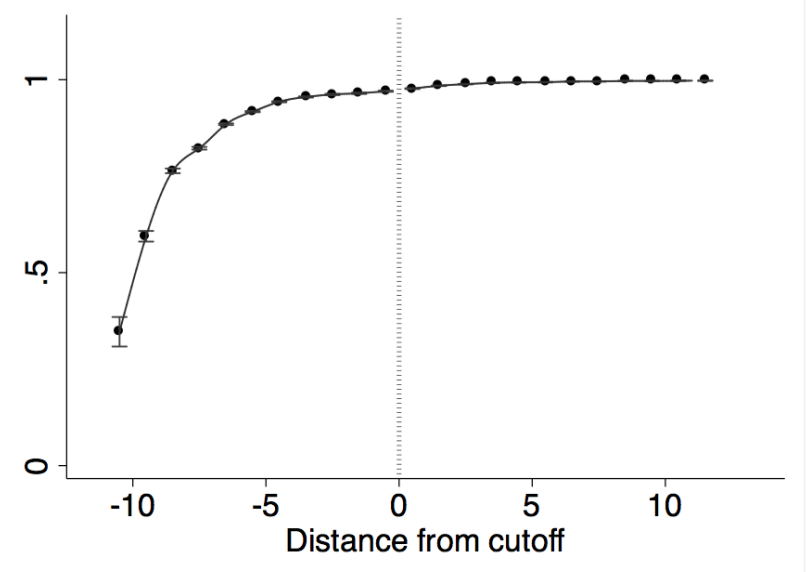

ECV 2010

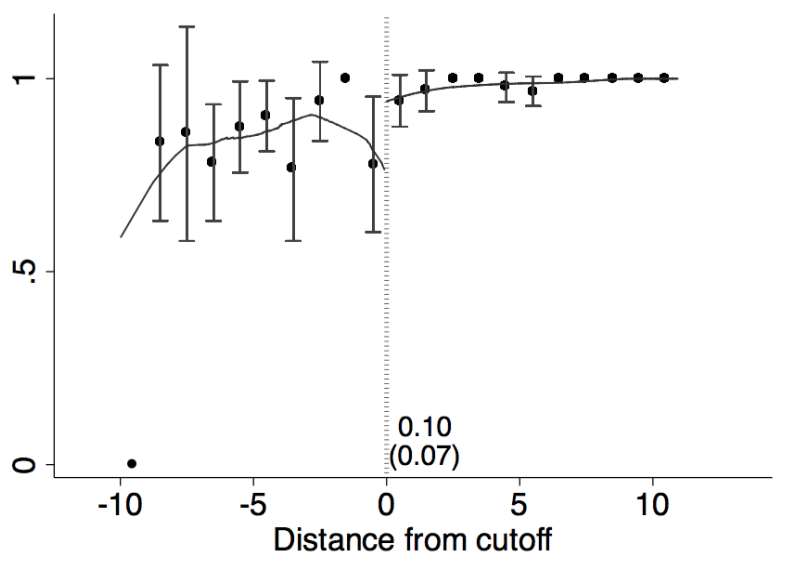

h: House has Toilet Connected to Sewage System 2005 SISBEN Census

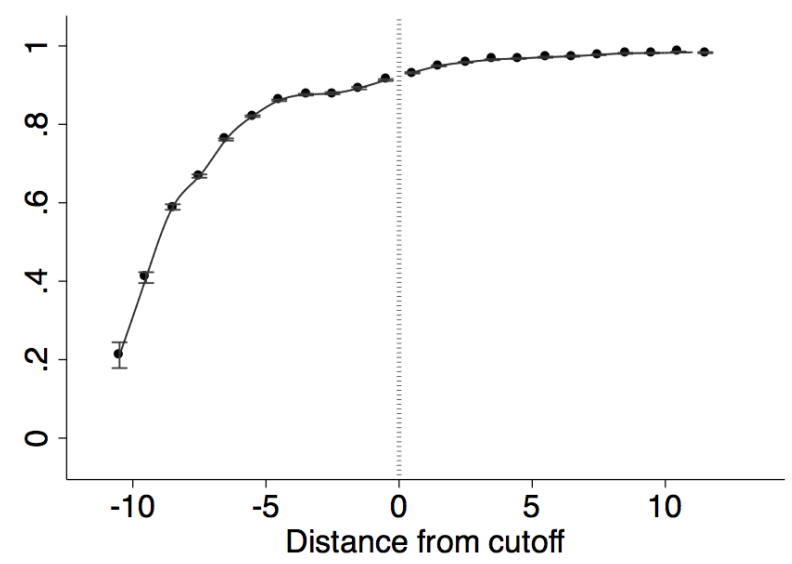

i: Number of Dormitories Per Person 2005 SISBEN Census

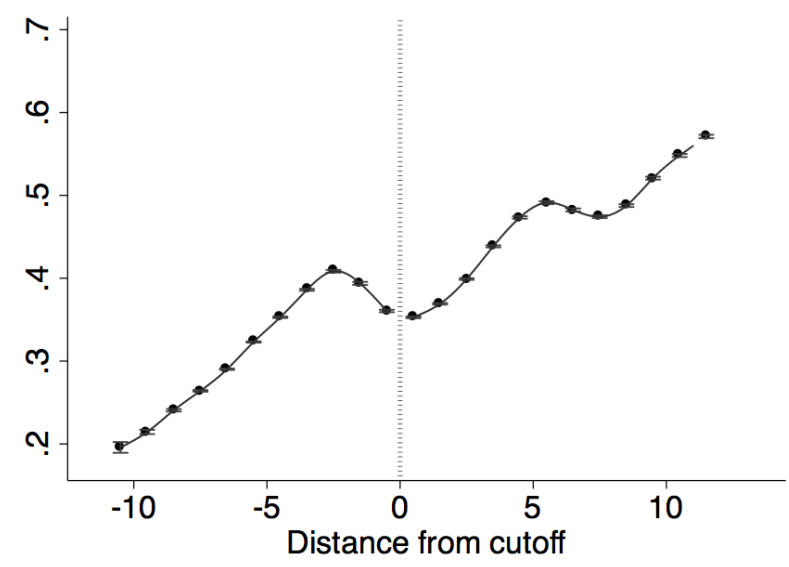

ECV 2010

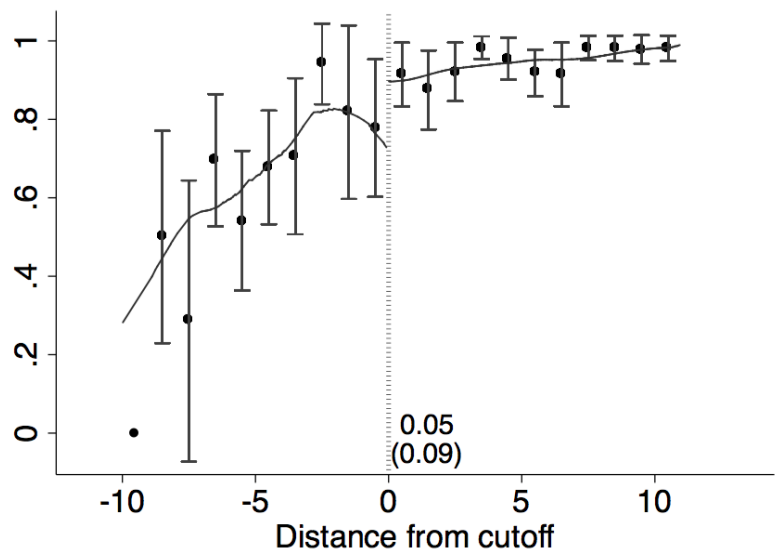

ECV 2010

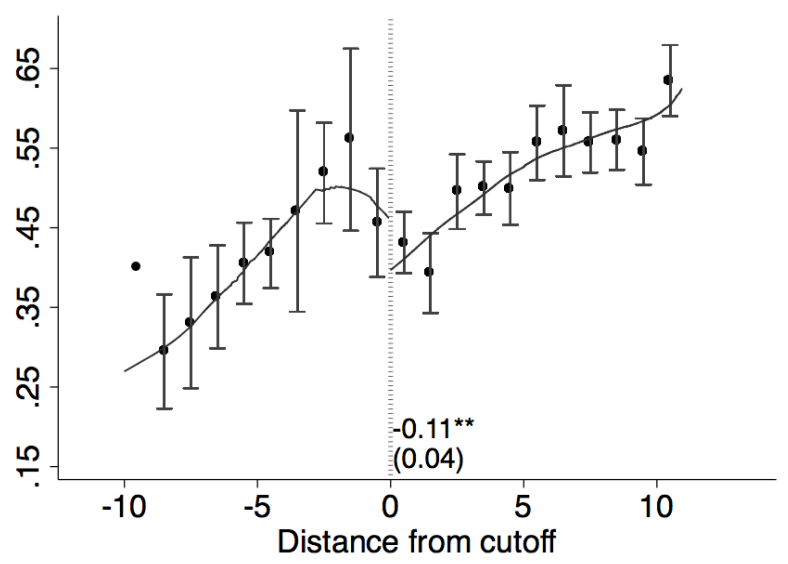




\section{j: House has Electricity \\ 2005 SISBEN Census}

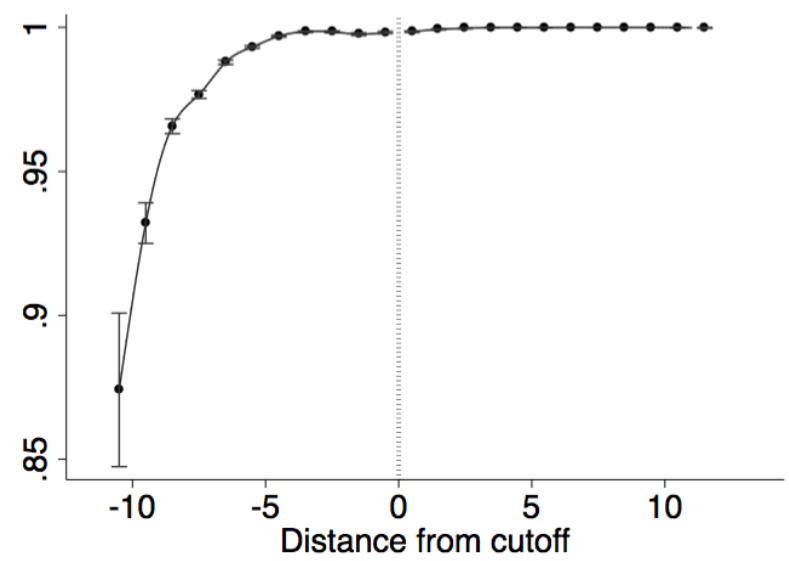

\section{k: House has Gas Connection} 2005 SISBEN Census

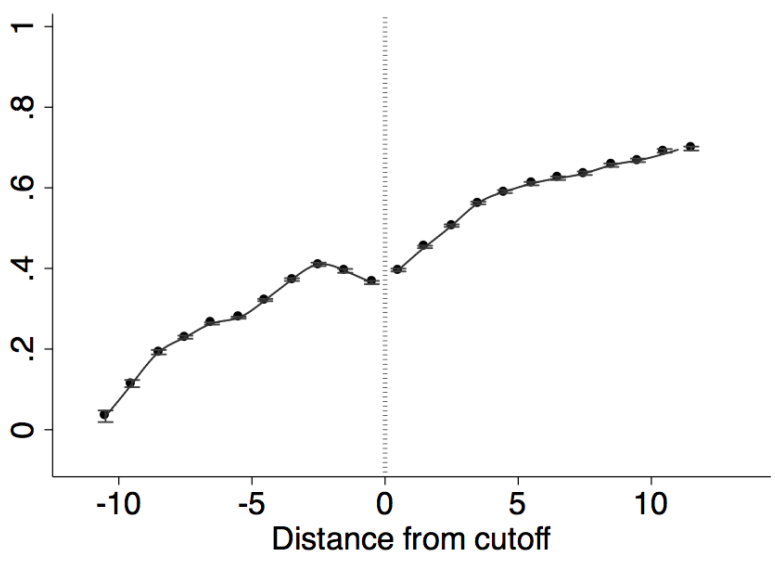

ECV 2010

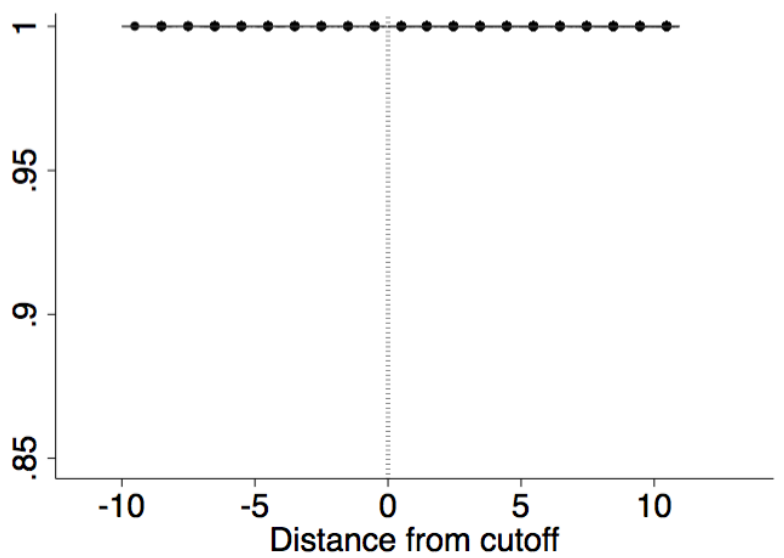

ECV 2010

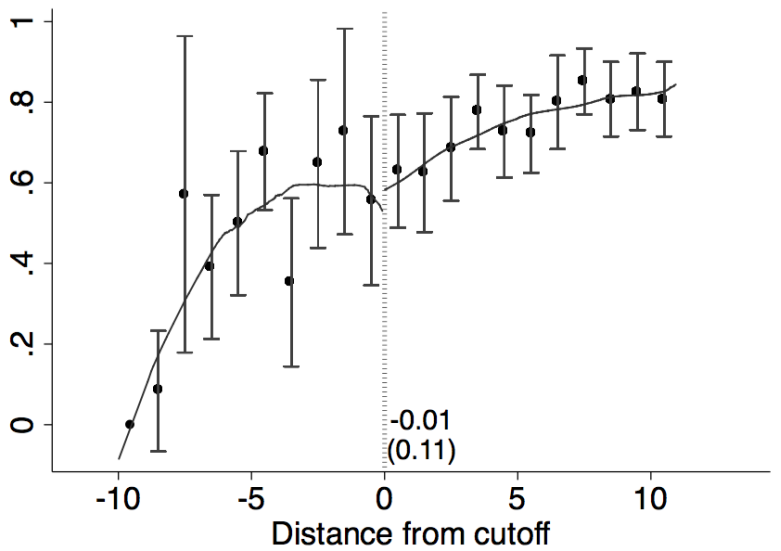

Notes: Data for the left panel is from the 2005 SISBEN census. Data for the right panel is from the ECV 2010 survey. Data in both panels are limited to households from all 14 cities included in the 2007 FAU expansion with children 18 years of age and younger and a SISBEN score under 22. Error bars represent $90 \%$ confidence intervals around the average variable in bin with one unit width. If no confidence interval is reported, there is no variance within the bin. Estimates of size of discontinuity are included in the ECV 2010 graphs with standard errors in parenthesis. No estimate is reported for house has electricity because there is no variation. SISBEN scores are expressed in terms of the distance from the 11-point eligibility cutoff (shown by the vertical line at zero). Lowess or spline curves are fit separately on either side of the eligibility cutoff. Due to computational limitations and a dataset with over 8 million observations, splines are fit to the average bin values in the left panel (2005 SISBEN census data). Lowess curves are fit to the raw data in the right panel (2010 ECV survey data). 
Appendix C. Supplementary Analysis

Figure C-1: Density of Households over SISBEN Scores, 2007 CNPD Baseline Survey

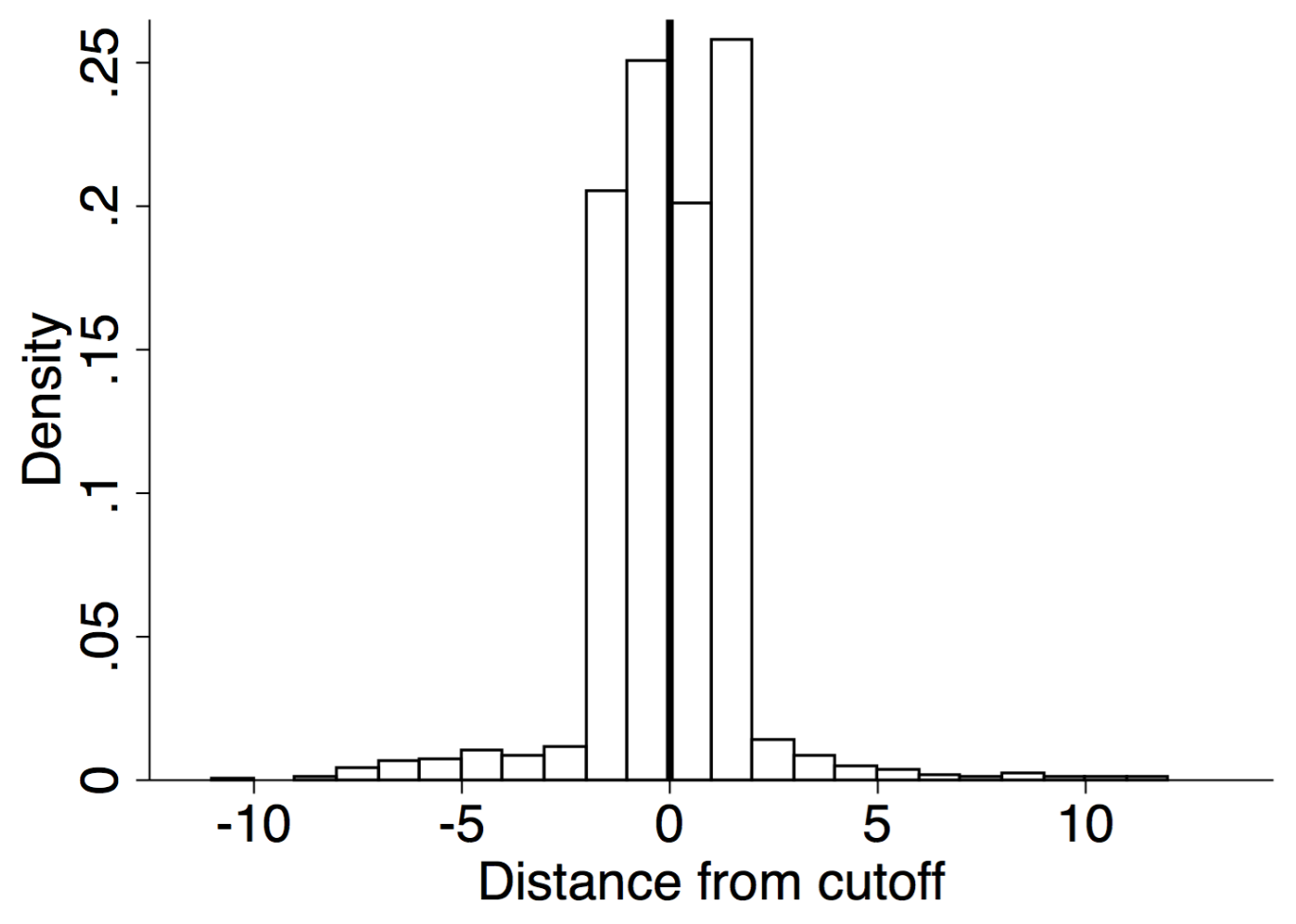


Table C1. Fuzzy RD Estimates of Participation on Income, Expenditure, and Formal Employment, Doughnut Hole -1 to 1

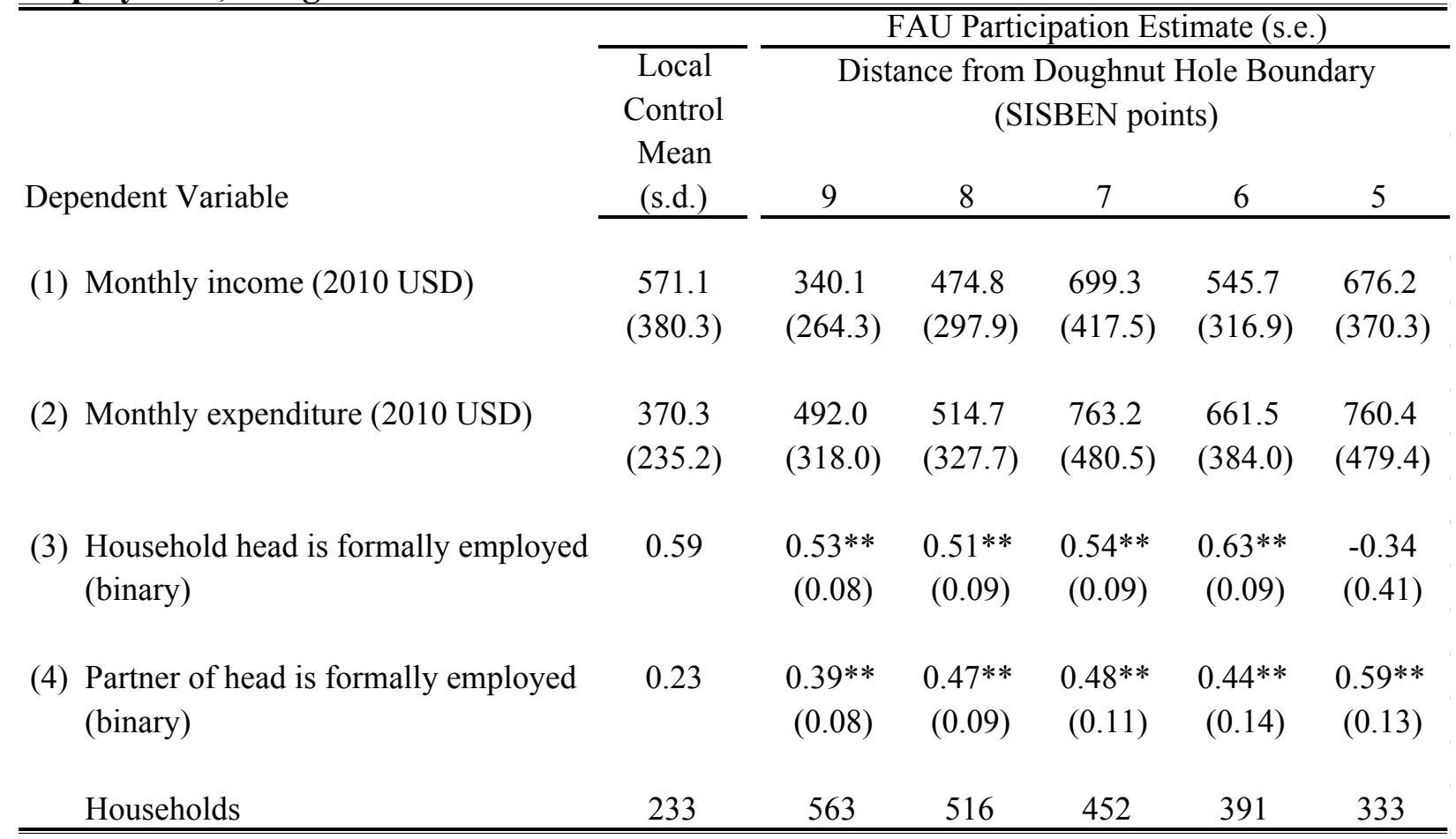

Notes: Data is from the ECV 2010 survey and at the household level. Sample restricted to households in the 2007 FAU expansion cities with a child age 18 and younger and SISBEN scores of 22 or lower. Doughnut hole is [-1,1] SISBEN points around FAU eligibility cutoff of 11 SISBEN points. Columns represent bandwidths between 5 and 9 SISBEN units from the doughnut hole boundary (on both sides). The estimates of FAU receipt effects are from separate regressions in which receipt is instrumented with an indicator for having a SISBEN score below 11 points (eligible). Estimates for monthly income and monthly expenditure are linear IV. Estimates for employment are bivariate probit, with the marginal probability of 1 reported at the cutoff. Other controls not shown include SISBEN score, an interaction of eligible with linear SISBEN score, and city (see equations 1 and 2 for first and second stage). The local control mean is the mean variable value for ineligible households within 5 SISBEN units of the doughnut hold boundary (single side, households above the doughnut hole). Standard deviation of control means are presented in parenthesis under the control means, and robust standard errors are presented in parenthesis under estimates. Number of observations for head formally employed variable are 293, 251, 212, 171, and 131 for bandwidths from 9 to 5 SISBEN units. Number of observations for partner of head formally employed variable are 260, 240, 215, 187, and 145 for bandwidths from 9 to 5 SISBEN units. Currency is converted to 2010 USD (see Appendix A for detail). Total expenditure is the sum of all expenditure categories. Expenditure items are defined in Appendix A. P-values are denoted by: $+\mathrm{p}<0.1, * \mathrm{p}<.05, * * \mathrm{p}<.01$. The critical values are corrected for multiple hypotheses testing using the method described in Benjamini and Hochberg (1995). Each column represents a family, and the corrected critical value levels for $0.1, .05$, and .01 are $.05, .025$, and .005 for bandwidth $9, .05, .025$, and .005 for bandwidth $8, .05, .025$, and .005 for bandwidth $7, .1, .025$, and .005 for bandwidth 6 , and $.025, .013$, and .0025 for bandwidth 5 . 
Table C2. Fuzzy RD Estimates of Participation on Health and Education Outcomes, Doughnut Hole -1 to 1

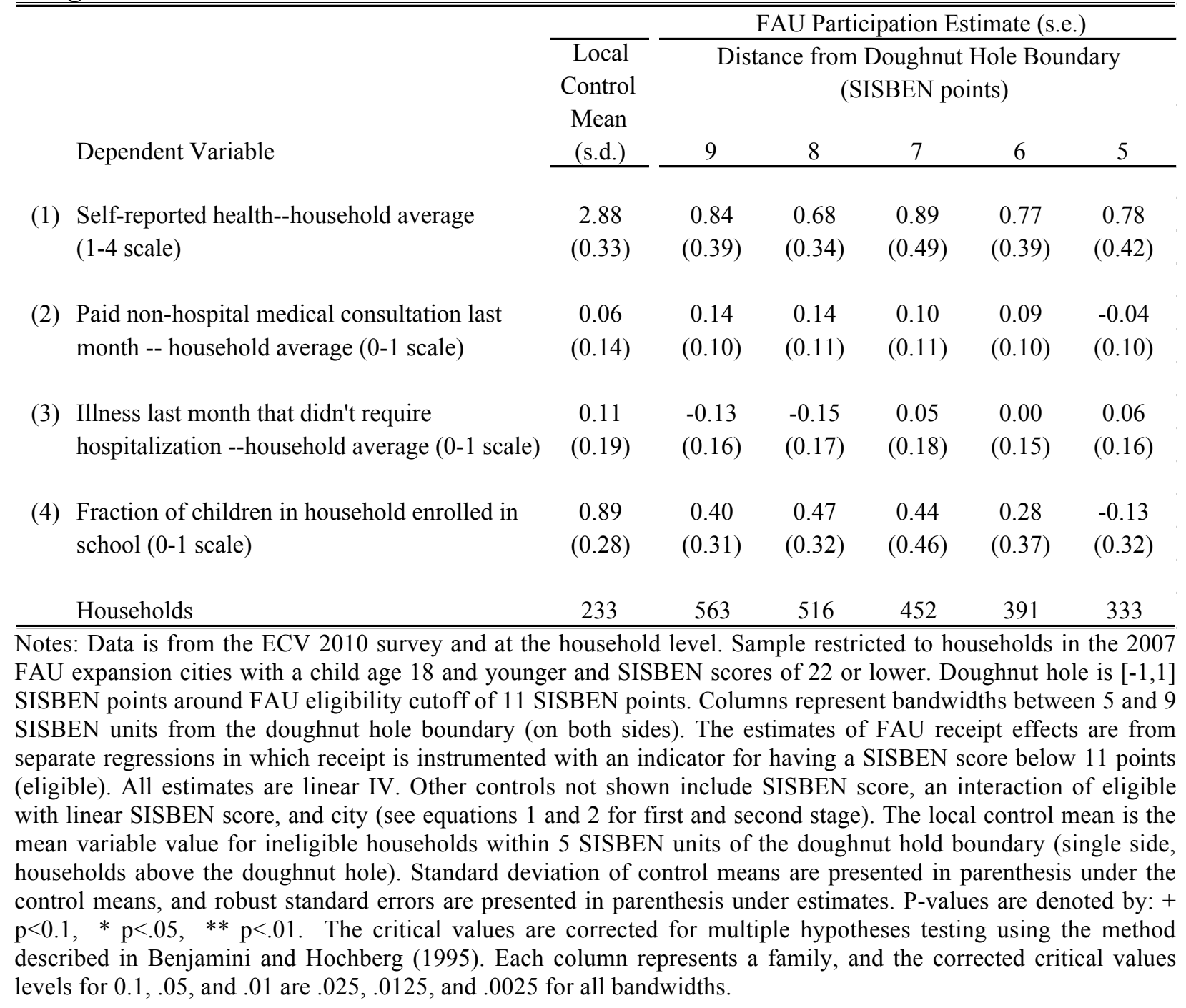


Table C3. Fuzzy RD Estimates of Participation on Household Head Domain Satisfaction Variables, Life Satisfaction, and Happiness, Doughnut Hole -1 to 1

\begin{tabular}{|c|c|c|c|c|c|c|c|}
\hline & & & & AU Parti & pation Es & imate $(\mathrm{s}$. & \\
\hline & & $\begin{array}{l}\text { Local } \\
\text { Control }\end{array}$ & Dis & $\begin{array}{r}\text { nce from } \\
(\mathrm{S}\end{array}$ & $\begin{array}{l}\text { Ooughnut } \\
\text { BEN poi }\end{array}$ & $\begin{array}{l}\text { Hole Bou } \\
\text { tts) }\end{array}$ & dary \\
\hline & Dependent Variable (all binary) & Mean & 9 & 8 & 7 & 6 & 5 \\
\hline$(1)$ & Satisfaction with life & 0.75 & $\begin{array}{l}0.46+ \\
(0.20)\end{array}$ & $\begin{array}{l}0.43 * \\
(0.17)\end{array}$ & $\begin{array}{l}0.49^{*} \\
(0.20)\end{array}$ & $\begin{array}{c}0.49^{* *} \\
(0.15)\end{array}$ & $\begin{array}{c}-0.40 \\
(1.03)\end{array}$ \\
\hline$(2)$ & Happiness & 0.77 & $\begin{array}{c}0.59 * * \\
(0.04)\end{array}$ & $\begin{array}{r}0.59 * * \\
(0.04)\end{array}$ & $\begin{array}{c}0.60 * * \\
(0.05)\end{array}$ & $\begin{array}{l}-0.13 \\
(0.33)\end{array}$ & $\begin{array}{c}-0.19 \\
(0.17)\end{array}$ \\
\hline (3) & Satisfaction with income & 0.25 & $\begin{array}{c}0.12 \\
(0.21)\end{array}$ & $\begin{array}{c}0.20 \\
(0.15)\end{array}$ & $\begin{array}{c}0.08 \\
(0.25)\end{array}$ & $\begin{array}{c}0.06 \\
(0.24)\end{array}$ & $\begin{array}{c}-0.08 \\
(0.29)\end{array}$ \\
\hline$(4)$ & Satisfaction with work & 0.49 & $\begin{array}{l}0.06 \\
(0.53)\end{array}$ & $\begin{array}{l}0.35 \\
(0.23)\end{array}$ & $\begin{array}{c}0.20 \\
(1.00)\end{array}$ & $\begin{array}{c}0.06 \\
(1.10)\end{array}$ & $\begin{array}{c}0.30 \\
(0.34)\end{array}$ \\
\hline$(5)$ & Satisfaction with food & 0.77 & $\begin{array}{r}0.56^{* *} \\
(0.04)\end{array}$ & $\begin{array}{r}0.56^{* *} \\
(0.04)\end{array}$ & $\begin{array}{r}0.57 * * \\
(0.05)\end{array}$ & $\begin{array}{r}0.53 * * \\
(0.06)\end{array}$ & $\begin{array}{c}0.00 \\
(0.00)\end{array}$ \\
\hline$(6)$ & $\begin{array}{l}\text { Satisfaction with level of control over } \\
\text { one's life }\end{array}$ & 0.88 & $\begin{array}{r}0.29 * * \\
(0.06)\end{array}$ & $\begin{array}{r}0.31 * * \\
(0.07)\end{array}$ & $\begin{array}{r}0.27 * * \\
(0.07)\end{array}$ & $\begin{array}{l}-0.07 \\
(0.04)\end{array}$ & $\begin{array}{l}-0.05 \\
(0.11)\end{array}$ \\
\hline$(8)$ & Satisfaction with ability to help others & 0.79 & $\begin{array}{l}0.35^{*} \\
(0.14)\end{array}$ & $\begin{array}{l}0.31 * \\
(0.14)\end{array}$ & $\begin{array}{c}0.32 \\
(0.25)\end{array}$ & $\begin{array}{c}0.19 \\
(0.22)\end{array}$ & $\begin{array}{c}0.26 \\
(0.19)\end{array}$ \\
\hline$(9)$ & Satisfaction with health & 0.79 & $\begin{array}{l}-0.38 \\
(0.18)\end{array}$ & $\begin{array}{c}-0.39 * * \\
(0.12)\end{array}$ & $\begin{array}{c}-0.39^{* *} \\
(0.13)\end{array}$ & $\begin{array}{c}-0.39^{*} \\
(0.15)\end{array}$ & $\begin{array}{c}-0.29 \\
(0.34)\end{array}$ \\
\hline (10) & Satisfaction with education & 0.76 & $\begin{array}{c}0.12 \\
(0.69)\end{array}$ & $\begin{array}{l}-0.04 \\
(0.92)\end{array}$ & $\begin{array}{c}0.39 \\
(0.31)\end{array}$ & $\begin{array}{c}0.35 \\
(0.21)\end{array}$ & $\begin{array}{r}0.49 * * \\
(0.13)\end{array}$ \\
\hline (11) & Satisfaction with community & 0.79 & $\begin{array}{l}-0.27 \\
(0.16)\end{array}$ & $\begin{array}{c}-0.14 \\
(0.26)\end{array}$ & $\begin{array}{l}-0.27 \\
(0.21)\end{array}$ & $\begin{array}{r}-0.35+ \\
(0.16)\end{array}$ & $\begin{array}{c}-0.14 \\
(0.31)\end{array}$ \\
\hline (12) & Satisfaction with level of security & 0.51 & $\begin{array}{l}-0.28 \\
(0.31)\end{array}$ & $\begin{array}{l}-0.14 \\
(0.45)\end{array}$ & $\begin{array}{c}0.59 * * \\
(0.04)\end{array}$ & $\begin{array}{c}0.04 \\
(0.57)\end{array}$ & $\begin{array}{c}0.07 \\
(0.52)\end{array}$ \\
\hline (13) & Satisfaction with friends & 0.79 & $\begin{array}{r}0.55^{* *} \\
(0.17)\end{array}$ & $\begin{array}{r}0.54 * * \\
(0.14)\end{array}$ & $\begin{array}{r}0.59 * * \\
(0.05)\end{array}$ & $\begin{array}{r}0.56^{* *} \\
(0.05)\end{array}$ & $\begin{array}{r}0.47^{* *} \\
(0.08)\end{array}$ \\
\hline
\end{tabular}


(14) Average Treatment Effect: Domain satisfaction variables (10 items)

(15) Average Treatment Effect: satisfaction with life and happiness (2 items)

Households

\begin{tabular}{rrrrrr}
0.70 & $0.41^{* *}$ & $0.41^{* *}$ & $0.49^{* *}$ & $0.21^{* *}$ & $0.28^{* *}$ \\
& $(0.03)$ & $(0.03)$ & $(0.02)$ & $(0.03)$ & $(0.05)$ \\
& & & & & \\
0.76 & $0.59^{* *}$ & $0.58^{* *}$ & $0.59^{* *}$ & $0.38+$ & -0.20 \\
& $(0.04)$ & $(0.04)$ & $(0.05)$ & $(0.14)$ & $(0.17)$ \\
& & & & & \\
233 & 563 & 516 & 452 & 391 & 333 \\
\hline
\end{tabular}

Notes: Data is from the ECV 2010 survey and at the household level. Sample restricted to households in the 2007 FAU expansion cities with a child age 18 and younger and SISBEN scores of 22 or lower. Doughnut hole is [-1,1] SISBEN points around FAU eligibility cutoff of 11 SISBEN points. Columns represent bandwidths between 5 and 9 SISBEN units from the doughnut hole boundary (on both sides). The estimates of FAU receipt effects are from separate regressions in which receipt is instrumented with an indicator for having a SISBEN score below 11 points (eligible). Estimates are bivariate probit, with the marginal probability of 1 reported at the cutoff. Other controls not shown include SISBEN score, an interaction of eligible with linear SISBEN score, and city (see equations 1 and 2 for first and second stage). The local control mean is the mean variable value for ineligible households within 5 SISBEN units of the doughnut hold boundary (single side, households above the doughnut hole). Satisfaction with level of dignity and satisfaction with family are not reported because there is very little variation when converted to a binary variable. Satisfaction with dwelling is not reported because it cannot be estimated. Robust standard errors are presented in parenthesis under estimates. Average treatment effects are variance-weighted averages and standard errors as described in Cooper et al. (2009). No weight is put on satisfaction with food for bandwidth 5 because the estimated effect and s.d. is 0 . P-values are denoted by: $+\mathrm{p}<0.1, * \mathrm{p}<.05, * * \mathrm{p}<.01$. The critical values are corrected for multiple hypotheses testing using the method described in Benjamini and Hochberg (1995). Each column represents a family, and the corrected critical value levels for $0.1, .05$, and .01 are $.025, .0125$, and .0025 for bandwidth $9, .058, .029$, and .003 for bandwidth $8, .058, .029$, and .005 for bandwidth $7, .058, .029$, and .006 for bandwidth 6 , and $.058, .029$, and .004 for bandwidth 5 . 
Table C4. Fuzzy RD Estimates of Participation on Income, Expenditure, and Formal Employment, Doughnut Hole -2 to 2

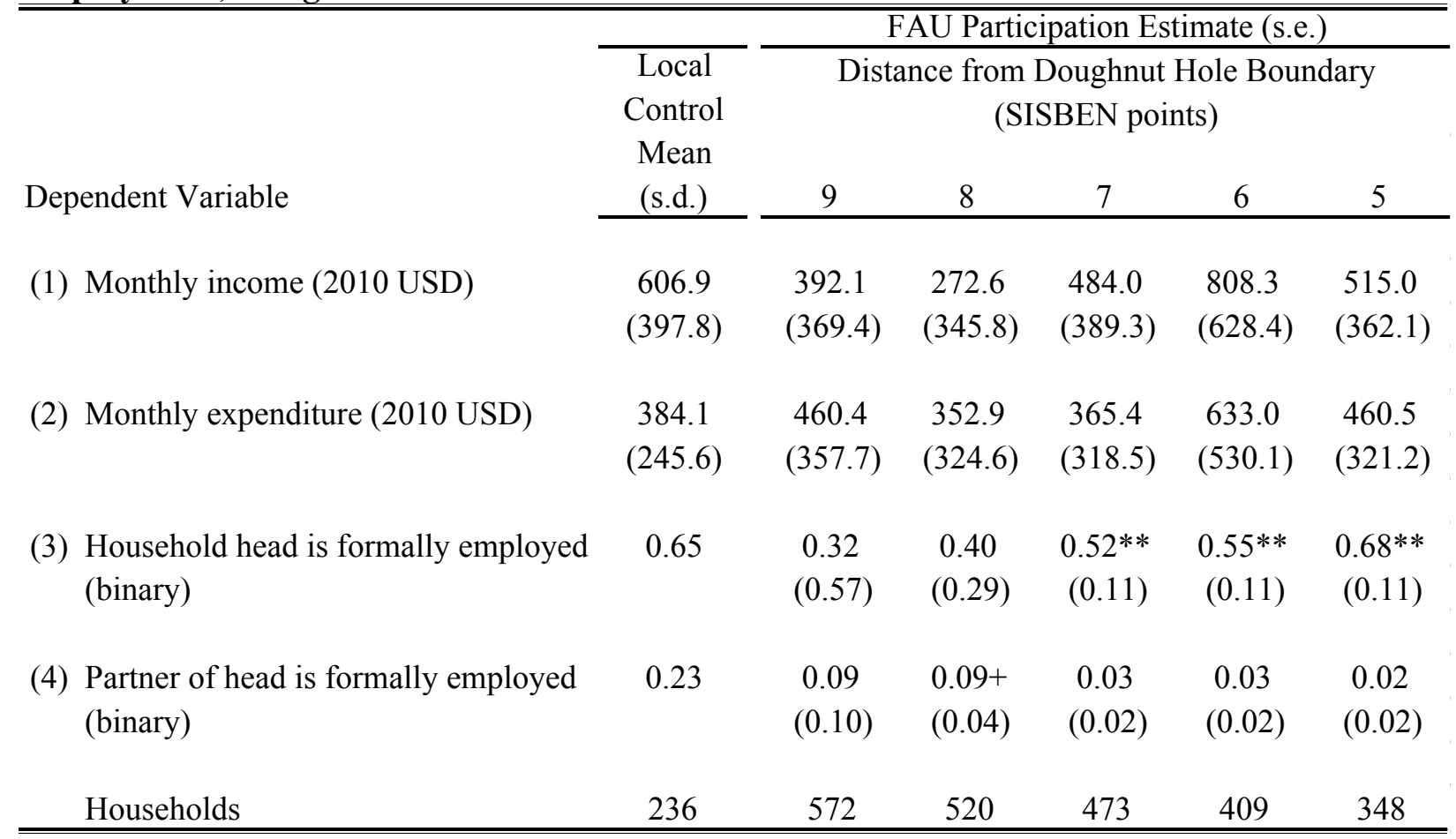

Notes: Data is from the ECV 2010 survey and at the household level. Sample restricted to households in the 2007 FAU expansion cities with a child age 18 and younger and SISBEN scores of 22 or lower. Doughnut hole is [-2,2] SISBEN points around FAU eligibility cutoff of 11 SISBEN points. Columns represent bandwidths between 5 and 9 SISBEN units from the doughnut hole boundary (on both sides). The estimates of FAU receipt effects are from separate regressions in which receipt is instrumented with an indicator for having a SISBEN score below 11 points (eligible). Estimates for monthly income and monthly expenditure are linear IV. Estimates for employment are bivariate probit, with the marginal probability of 1 reported at the cutoff. Other controls not shown include SISBEN score, an interaction of eligible with linear SISBEN score, and city (see equations 1 and 2 for first and second stage). The local control mean is the mean variable value for ineligible households within 5 SISBEN units of the doughnut hold boundary (single side, households above the doughnut hole). Standard deviation of control means are presented in parenthesis under the control means, and robust standard errors are presented in parenthesis under estimates. Number of observations for head formally employed variable are 287, 245, 210, 168, and 133 for bandwidths from 9 to 5 SISBEN units. Number of observations for partner of head formally employed variable are 257, 238, 217, 189, and 160 for bandwidths from 9 to 5 SISBEN units. Currency is converted to 2010 USD (see Appendix A for detail). Total expenditure is the sum of all expenditure categories. Expenditure items are defined in Appendix A. P-values are denoted by: $+\mathrm{p}<0.1, * \mathrm{p}<.05, * * \mathrm{p}<.01$. The critical values are corrected for multiple hypotheses testing using the method described in Benjamini and Hochberg (1995). Each column represents a family, and the corrected critical values levels for $0.1, .05$, and .01 are $.05, .0125$, and .005 for bandwidth $9, .05, .125$, and .005 for bandwidth $8, .05, .025$, and .005 for bandwidth $7, .025, .025$, and .0025 for bandwidth 6 , and $.025, .025$, and .0025 for bandwidth 5 . 
Table C5. Fuzzy RD Estimates of Participation on Health and Education Outcomes, Doughnut Hole -2 to 2

\begin{tabular}{|c|c|c|c|c|c|c|c|}
\hline & & & & AU Parti & pation Es & mate (s.e & \\
\hline & & $\begin{array}{l}\text { Local } \\
\text { Control }\end{array}$ & Dist: & $\begin{array}{r}\text { nce from } \\
(\mathrm{S})\end{array}$ & $\begin{array}{l}\text { oughnut } \\
\text { BEN poi }\end{array}$ & $\begin{array}{l}\text { ole Bou } \\
\text { s) }\end{array}$ & lary \\
\hline & Dependent Variable & (s.d.) & 9 & 8 & 7 & 6 & 5 \\
\hline (1) & $\begin{array}{l}\text { Self-reported health--household average } \\
\text { (1-4 scale) }\end{array}$ & $\begin{array}{c}2.91 \\
(0.33)\end{array}$ & $\begin{array}{l}1.07 \\
(0.61)\end{array}$ & $\begin{array}{l}0.91 \\
(0.57)\end{array}$ & $\begin{array}{l}0.62 \\
(0.42)\end{array}$ & $\begin{array}{c}0.91 \\
(0.69)\end{array}$ & $\begin{array}{l}0.62 \\
(0.41)\end{array}$ \\
\hline (2) & $\begin{array}{l}\text { Paid non-hospital medical consultation last } \\
\text { month -- household average }(0-1 \text { scale })\end{array}$ & $\begin{array}{c}0.07 \\
(0.16)\end{array}$ & $\begin{array}{l}0.30 \\
(0.19)\end{array}$ & $\begin{array}{l}0.30 \\
(0.20)\end{array}$ & $\begin{array}{c}0.30 \\
(0.20)\end{array}$ & $\begin{array}{l}0.29 \\
(0.25)\end{array}$ & $\begin{array}{l}0.22 \\
(0.16)\end{array}$ \\
\hline (3) & $\begin{array}{l}\text { Illness last month that didn't require } \\
\text { hospitalization --household average ( } 0 \text { - } 1 \text { scale) }\end{array}$ & $\begin{array}{c}0.12 \\
(0.19)\end{array}$ & $\begin{array}{l}-0.34 \\
(0.25)\end{array}$ & $\begin{array}{l}-0.37 \\
(0.27)\end{array}$ & $\begin{array}{l}-0.37 \\
(0.27)\end{array}$ & $\begin{array}{l}-0.17 \\
(0.24)\end{array}$ & $\begin{array}{l}-0.18 \\
(0.18)\end{array}$ \\
\hline (4) & $\begin{array}{l}\text { Fraction of children in household enrolled in } \\
\text { school (0-1 scale) }\end{array}$ & $\begin{array}{c}0.89 \\
(0.29)\end{array}$ & $\begin{array}{l}0.73 \\
(0.45)\end{array}$ & $\begin{array}{l}0.75 \\
(0.47)\end{array}$ & $\begin{array}{l}0.85 \\
(0.48)\end{array}$ & $\begin{array}{l}1.04 \\
(0.92)\end{array}$ & $\begin{array}{c}0.68 \\
(0.51)\end{array}$ \\
\hline & Households & 236 & 572 & 520 & 473 & 409 & 348 \\
\hline $\begin{array}{l}\text { SISB } \\
\text { separ } \\
\text { (eligi } \\
\text { with } \\
\text { mean } \\
\text { hous } \\
\text { contr }\end{array}$ & $\begin{array}{l}\text { is from the ECV } 2010 \text { survey and at the house } \\
\text { nsion cities with a child age } 18 \text { and younger } \\
\text { EN points around FAU eligibility cutoff of } 11 \mathrm{~S} \\
\text { EN units from the doughnut hole boundary (o } \\
\text { ate regressions in which receipt is instrumented } \\
\text { ible). All estimates are linear IV. Other control } \\
\text { linear SISBEN score, and city (see equations } 1 \\
\text { variable value for ineligible households within } \\
\text { eholds above the doughnut hole). Standard devi } \\
\text { ol means, and robust standard errors are presen } \\
1, * \text { p }<.05, * * \text { p }<.01 \text {. The critical values ar } \\
\text { ibed in Benjamini and Hochberg (1995). Each }\end{array}$ & $\begin{array}{l}\text { ISBEN p } \\
\text { both si } \\
\text { with an } \\
\text { not sho } \\
\text { and } 2 \text { for } \\
5 \text { SISB } \\
\text { ation of } \\
\text { ed in pa } \\
\text { correct }\end{array}$ & $\begin{array}{l}\text { Colu } \\
\text { The } \\
\text { ator fo } \\
\text { include } \\
\text { and se } \\
\text { inits of } \\
\text { rol me } \\
\text { iesis ur } \\
\text { or mul }\end{array}$ & $\begin{array}{l}\text { repre } \\
\text { mates } \\
\text { aving } \\
\text { SBEN } \\
\text { hd stą } \\
\text { e doug } \\
\text { are p1 } \\
r \text { estim } \\
\text { hypc }\end{array}$ & $\begin{array}{l}\text { bandw } \\
\text { AU re } \\
\text { BEN } \\
\text { re, an } \\
\text { he loc } \\
\text { hold } \\
\text { ted in } \\
\text { P-val }\end{array}$ & $\begin{array}{l}\text { hs betv } \\
\text { pt effe } \\
\text { re belo } \\
\text { eractio } \\
\text { control } \\
\text { indary } \\
\text { renthes } \\
\text { are d }\end{array}$ & $\begin{array}{l}007 \text { FAU } \\
\text { is }[-2,2] \\
\text { n } 5 \text { and } 9 \\
\text { are from } \\
11 \text { points } \\
\text { f eligible } \\
\text { ean is the } \\
\text { ngle side, } \\
\text { under the } \\
\text { ted by: }\end{array}$ \\
\hline
\end{tabular}


Table C6. Effect of FAU Subsidy on Household Head Domain Satisfaction Variables, Life Satisfaction, and Happiness, Doughnut Hole -2 to 2

\begin{tabular}{|c|c|c|c|c|c|c|c|}
\hline \multirow{3}{*}{\multicolumn{2}{|c|}{ Dependent Variable (all binary) }} & \multirow{3}{*}{$\begin{array}{c}\text { Local } \\
\text { Control } \\
\text { Mean } \\
\end{array}$} & \multicolumn{5}{|c|}{ FAU Participation Estimate (s.e.) } \\
\hline & & & \multicolumn{5}{|c|}{$\begin{array}{l}\text { Distance from Doughnut Hole Boundary } \\
\text { (SISBEN points) }\end{array}$} \\
\hline & & & 9 & 8 & 7 & 6 & 5 \\
\hline (1) & Satisfaction with life & 0.78 & $\begin{array}{r}0.56^{* *} \\
(0.04)\end{array}$ & $\begin{array}{r}0.56 * * \\
(0.04)\end{array}$ & $\begin{array}{r}0.55^{* *} \\
(0.05)\end{array}$ & $\begin{array}{r}0.58 * * \\
(0.05)\end{array}$ & $\begin{array}{r}0.50 * * \\
(0.07)\end{array}$ \\
\hline (2) & Happiness & 0.78 & $\begin{array}{l}-0.23 \\
(0.38)\end{array}$ & $\begin{array}{c}0.02 \\
(1.05)\end{array}$ & $\begin{array}{l}0.18 \\
(2.01)\end{array}$ & $\begin{array}{l}-0.14 \\
(0.54)\end{array}$ & $\begin{array}{l}-0.35 \\
(0.35)\end{array}$ \\
\hline (3) & Satisfaction with income & 0.27 & $\begin{array}{l}0.13 \\
(0.26)\end{array}$ & $\begin{array}{c}0.23 \\
(0.23)\end{array}$ & $\begin{array}{l}0.26 \\
(0.18)\end{array}$ & $\begin{array}{l}0.15 \\
(0.26)\end{array}$ & $\begin{array}{c}0.11 \\
(0.22)\end{array}$ \\
\hline (4) & Satisfaction with work & 0.50 & $\begin{array}{l}-0.17 \\
(0.46)\end{array}$ & $\begin{array}{l}-0.35 \\
(0.35)\end{array}$ & $\begin{array}{l}0.10 \\
(0.51)\end{array}$ & $\begin{array}{c}-0.56^{* *} \\
(0.11)\end{array}$ & $\begin{array}{c}-0.58 * * \\
(0.05)\end{array}$ \\
\hline (5) & Satisfaction with food & 0.81 & $\begin{array}{r}0.58^{* *} \\
(0.05)\end{array}$ & $\begin{array}{r}0.56^{* *} \\
(0.05)\end{array}$ & $\begin{array}{r}0.56^{* *} \\
(0.05)\end{array}$ & $\begin{array}{r}0.56^{* *} \\
(0.06)\end{array}$ & $\begin{array}{r}0.48^{* *} \\
(0.09)\end{array}$ \\
\hline (6) & $\begin{array}{l}\text { Satisfaction with level of control over } \\
\text { one's life }\end{array}$ & 0.89 & $\begin{array}{l}-0.09 \\
(0.31)\end{array}$ & $\begin{array}{c}0.01 \\
(0.72)\end{array}$ & $\begin{array}{l}-0.04 \\
(0.32)\end{array}$ & $\begin{array}{c}-0.21+ \\
(0.10)\end{array}$ & $\begin{array}{l}-0.14 \\
(0.08)\end{array}$ \\
\hline (7) & Satisfaction with dwelling & 0.71 & $\begin{array}{c}0.56^{* *} \\
(0.04)\end{array}$ & $\begin{array}{r}0.57 * * \\
(0.04)\end{array}$ & $\begin{array}{c}0.56^{* *} \\
(0.04)\end{array}$ & $\begin{array}{c}0.57 * * \\
(0.04)\end{array}$ & $\begin{array}{r}0.55^{* *} \\
(0.05)\end{array}$ \\
\hline (8) & Satisfaction with ability to help others & 0.81 & $\begin{array}{c}0.20 \\
(0.19)\end{array}$ & $\begin{array}{c}0.26 \\
(0.19)\end{array}$ & $\begin{array}{c}0.23 \\
(0.17)\end{array}$ & $\begin{array}{c}0.11 \\
(0.34)\end{array}$ & $\begin{array}{l}-0.02 \\
(0.27)\end{array}$ \\
\hline$(9)$ & Satisfaction with health & 0.78 & $\begin{array}{c}-0.43 * * \\
(0.12)\end{array}$ & $\begin{array}{c}-0.44 * * \\
(0.12)\end{array}$ & $\begin{array}{c}-0.42 * * \\
(0.11)\end{array}$ & $\begin{array}{c}-0.41 * * \\
(0.14)\end{array}$ & $\begin{array}{c}-0.39 * \\
(0.14)\end{array}$ \\
\hline (10) & Satisfaction with family & 0.93 & $\begin{array}{c}0.03 \\
(0.03)\end{array}$ & $\begin{array}{c}0.02 \\
(0.02)\end{array}$ & $\begin{array}{c}0.01 \\
(0.02)\end{array}$ & $\begin{array}{c}0.01 \\
(0.01)\end{array}$ & $\begin{array}{l}0.00 \\
0.00\end{array}$ \\
\hline (11) & Satisfaction with education & 0.78 & $\begin{array}{c}-0.29+ \\
(0.15)\end{array}$ & $\begin{array}{c}0.50 * * \\
(0.06)\end{array}$ & $\begin{array}{l}-0.17 \\
(1.30)\end{array}$ & $\begin{array}{c}0.48 * * \\
(0.07)\end{array}$ & $\begin{array}{c}0.25 \\
(0.19)\end{array}$ \\
\hline (12) & Satisfaction with community & 0.78 & $\begin{array}{l}-0.36^{*} \\
(0.14)\end{array}$ & $\begin{array}{r}-0.33+ \\
(0.18)\end{array}$ & $\begin{array}{l}-0.24 \\
(0.28)\end{array}$ & $\begin{array}{c}-0.41+ \\
(0.21)\end{array}$ & $\begin{array}{c}-0.46^{*} \\
(0.19)\end{array}$ \\
\hline (13) & Satisfaction with level of security & 0.53 & $\begin{array}{l}-0.44 \\
(0.26)\end{array}$ & $\begin{array}{l}-0.38 \\
(0.40)\end{array}$ & $\begin{array}{l}-0.11 \\
(0.88)\end{array}$ & $\begin{array}{c}0.62 * * \\
(0.04)\end{array}$ & $\begin{array}{c}0.25 \\
(0.73)\end{array}$ \\
\hline
\end{tabular}


(14) Satisfaction with friends

(15) Average Treatment Effect: Domain satisfaction variables (11 items)

(16) Average Treatment Effect: satisfaction with life and happiness (2 items)

\begin{tabular}{rrrrrc}
0.83 & $0.41^{*}$ & $0.45^{* *}$ & $0.44^{* *}$ & $0.45^{* *}$ & $0.34^{*}$ \\
& $(0.16)$ & $(0.12)$ & $(0.13)$ & $(0.08)$ & $(0.12)$ \\
& & & & & \\
0.72 & $0.41^{* *}$ & $0.47^{* *}$ & $0.46^{* *}$ & $0.45^{* *}$ & 0.02 \\
& $(0.03)$ & $(0.03)$ & $(0.03)$ & $(0.02)$ & $(0.03)$ \\
& & & & & \\
0.78 & $0.55^{* *}$ & $0.56^{* *}$ & $0.55^{* *}$ & $0.57^{* *}$ & $0.47^{* *}$ \\
& $(0.04)$ & $(0.04)$ & $(0.05)$ & $(0.05)$ & $(0.07)$ \\
& & & & & \\
236 & 572 & 520 & 473 & 409 & 348 \\
\hline
\end{tabular}

Households

(1)

\begin{abstract}
Notes: Data is from the ECV 2010 survey and at the household level. Sample restricted to households in the 2007 FAU expansion cities with a child age 18 and younger and SISBEN scores of 22 or lower. Doughnut hole is [-2,2] SISBEN points around FAU eligibility cutoff of 11 SISBEN points. Columns represent bandwidths between 5 and 9 SISBEN units from the doughnut hole boundary (on both sides). The estimates of FAU receipt effects are from separate regressions in which receipt is instrumented with an indicator for having a SISBEN score below 11 points (eligible). Estimates are bivariate probit, with the marginal probability of 1 reported at the cutoff. Other controls not shown include SISBEN score, an interaction of eligible with linear SISBEN score, and city (see equations 1 and 2 for first and second stage). The local control mean is the mean variable value for ineligible households within 5 SISBEN units of the doughnut hold boundary (single side, households above the doughnut hole). Satisfaction with level of dignity and satisfaction with family are not reported because there is very little variation when converted to a binary variable. Robust standard errors are presented in parenthesis under estimates. Average treatment effects are variance-weighted averages and standard errors as described in Cooper et al. (2009). No weight is put on satisfaction with food for bandwidth 5 becuase the estimated effect and s.d. is 0 . P-values are denoted by: $+\mathrm{p}<0.1, *$ $\mathrm{p}<.05,{ }^{* *} \mathrm{p}<.01$. The critical values are corrected for multiple hypotheses testing using the method described in Benjamini and Hochberg (1995). Each column represents a family, and the corrected critical value levels for 0.1, .05 , and .01 are $.069, .031$, and .006 for bandwidth $9, .077, .038$, and .007 for bandwidth $8, .038, .019$, and .004 for bandwidth $7, .054, .023$, and .005 for bandwidth 6 , and $.054, .027$, and .004 for bandwidth 5 .
\end{abstract}

